\title{
Mechanisms of Small Heat Shock Proteins
}

\author{
Maria K. Janowska, Hannah E.R. Baughman, Christopher N. Woods, and Rachel E. Klevit \\ Department of Biochemistry, University of Washington, Seattle, Washington 98195 \\ Correspondence: klevit@uw.edu
}

Small heat shock proteins (sHSPs) are ATP-independent chaperones that delay formation of harmful protein aggregates. sHSPs' role in protein homeostasis has been appreciated for decades, but their mechanisms of action remain poorly understood. This gap in understanding is largely a consequence of sHSP properties that make them recalcitrant to detailed study. Multiple stress-associated conditions including $\mathrm{pH}$ acidosis, oxidation, and unusual availability of metal ions, as well as reversible stress-induced phosphorylation can modulate sHSP chaperone activity. Investigations of sHSPs reveal that sHSPs can engage in transient or longlived interactions with client proteins depending on solution conditions and sHSP or client identity. Recent advances in the field highlight both the diversity of function within the sHSP family and the exquisite sensitivity of individual sHSPs to cellular and experimental conditions. Here, we will present and highlight current understanding, recent progress, and future challenges.

\begin{abstract}
lthough small heat shock proteins (sHSPs) Awere recognized as protein chaperones a quarter century ago (Horwitz 1992; Jakob et al. 1993), understanding how they work at a molecular level has been slow to emerge. sHSPs are defined by their shared $\alpha$-crystallin domain (ACD), named after the highly abundant sHSPs in the eye lens, $\alpha \mathrm{A}$-crystallin (referred to here by its gene name, HSBP4) and $\alpha \mathrm{B}$-crystallin (HSPB5) (Caspers et al. 1995). sHSPs are ATPindependent chaperones that can delay the onset of irreversible protein aggregation in response to cellular stressors. Mutations in sHSPs are linked to multiple diseases, including various neuropathies and early-onset cataract formation, implying that sHSP dysfunction can have dire consequences (Litt et al. 1998; Vicart et al. 1998; Irobi et al. 2004; Kijima et al. 2005; Hansen et al. 2007; Houlden et al. 2008; Datskevich
\end{abstract}

et al. 2012). sHSPs are implicated in muscle protection, their expression is associated with poor prognosis and treatment resistance in cancer, and they play ameliorative roles in Parkinson's and Alzheimer's disease (Zoubeidi and Gleave 2012; Dubińska-Magiera et al. 2014; Leak 2014). Transcription of some, but not all, sHSPs is under the control of the heat shock factor (HSF) transcription factors, which can upregulate the cellular concentrations of an sHSP in response to stress (Table 1) (De Thonel et al. 2012; Zhong et al. 2016). In addition, sHSPs themselves are exquisitely sensitive to their conditions, and their activity, as well as their protein levels, is activated by cellular conditions (Haslbeck et al. 2005; Treweek et al. 2015). Genomes across biology contain varying numbers of sHSPs: Escherichia coli and Saccharomyces cerevisiae each have two; Drosophila melanogaster

Editors: Richard I. Morimoto, F. Ulrich Hartl, and Jeffery W. Kelly

Additional Perspectives on Protein Homeostasis available at www.cshperspectives.org

Copyright (C) 2019 Cold Spring Harbor Laboratory Press; all rights reserved; doi: 10.1101/cshperspect.a034025

Cite this article as Cold Spring Harb Perspect Biol 2019;11:a034025 
M.K. Janowska et al.

Table 1. Basic information regarding human small heat shock proteins (sHSPs)

\begin{tabular}{lllc}
\hline Gene name & \multicolumn{1}{c}{ Other names } & \multicolumn{1}{c}{ Tissue distribution } & Heat shock factor (HSF) inducible \\
\hline HSPB1 & Hsp25, Hsp27, Hsp28 & Ubiquitous & HSF-1, HSF-2 \\
HSPB2 & MKBP & Cardiac and skeletal muscle & \\
HSPB3 & HSPL27 & Cardiac and skeletal muscle & \\
HSPB4 & $\alpha$ A-crystallin & Eye lens & \\
HSPB5 & $\alpha B$-crystallin & Ubiquitous & HSF-1 \\
HSPB6 & Hsp20, p20 & Ubiquitous & \\
HSPB7 & cvHsp & Cardiac and skeletal muscle & HSF-1 \\
HSPB8 & Hsp22 & Ubiquitous & \\
HSPB9 & CT51 & Testis & \\
HSPB10 & ODF1 & Testis & \\
\hline
\end{tabular}

has 12; Caenorhabditis elegans has 16; and Arabidopsis thaliana has 25 (Susek and Lindquist 1989; Laskowska et al. 1996; Wotton et al. 1996; Scharf et al. 2001; Candido 2002; Michaud et al. 2002). The ten human sHSPs differ in their tissue distribution and response to specific stressors (see Table 1) (Kappé et al. 2003).

Recent studies have begun to define how sHSPs become activated and how they recognize "clients" (the proteins on which they act) (Mainz et al. 2012; Peschek et al. 2013; Rajagopal et al. 2015b). Such studies are proving to be highly informative, although their interpretation in terms of general models for sHSP activity has proven challenging. As sHSPs act as early responders to help cells cope with proteins that are destabilized because of a stress condition, the "client-ome" could be vast, diverse, and different depending on the state of the cell before the stress. The sheer diversity of potential clients makes it unclear whether results obtained on specific systems can be generalized to other sHSP systems and whether it is sensible to try to do so. Here, we discuss emerging models and outstanding questions regarding sHSP mechanisms and suggest strategies to leverage both technological and scientific developments to improve understanding of these enigmatic but critical proteins.

\section{sHSP STRUCTURE}

sHSPs Have Unusual Structural Properties

Like all sHSPs, the human sHSPs share a domain architecture in which a highly variable amino- terminal region (NTR) and a flexible carboxyterminal region (CTR) flank the structured ACD (Fig. 1). The three domains show distinct behaviors that arise, at least in part, from their distinct amino acid content. The ACD is the only natively folded region, forming an IgGlike $\beta$-sandwich structure (Fig. 1B). ACDs of human sHSPs are enriched in histidines that may give rise to an ability to respond to changes in $\mathrm{pH}$ and in metal ion availability to modulate sHSP activity (Fig. 1A). The CTR is enriched in polar and charged residues, is highly disordered, and is thought to serve as a solubility tag to enable the extremely high concentrations of sHSP found in tissues such as eye lens (>150 mg/ $\mathrm{mL}$ ) to remain soluble (Smulders et al. 1996; Horwitz 2003). NTRs are enriched in hydrophobic residues and are disordered (Bloemendal 1977). Despite their simple architecture, sHSPs are structurally complicated. Human sHSPs exist in a range of oligomeric states. Some, including HSPB1, HSPB4, and HSPB5, form polydisperse ensembles of oligomers that range in size from dimers to 440 -mers (Aquilina et al. 2003; Horwitz 2003; Jovcevski et al. 2015). These oligomeric ensembles are highly dynamic with frequent subunit exchange between oligomers ( $\mathrm{Pe}$ schek et al. 2013). Other sHSPs, such as HSPB8 and HSPB6 exist predominantly as small oligomers or dimers (Bukach et al. 2004). To date, there is no evidence of an sHSP that exists predominantly as a monomer, but such species may exist fleetingly as subunits exchange from one oligomer to another (Bova et al. 1997).

Although oligomeric mammalian sHSPs are recalcitrant to conventional structural biology 


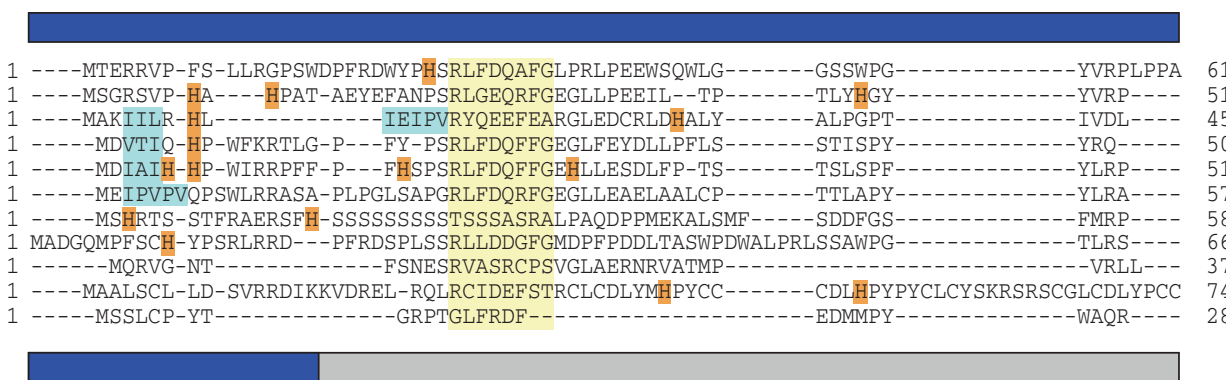

HSPB1 62 AIESPAVAAPAYSRALSRQLSSGV----SEIRḦTADRWRVS-_-_-_o O O HSPB2 52 - -

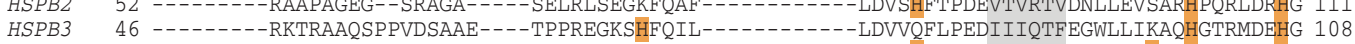
HSPB4 51 -HSPB5 52 -------PSFLRAPSW-FDTGL----SEMRLEKDRFSVN---------LDVKHFSPEELKVKVLGDVIEVHGKHEERQDEHG 112 HSPB 58 -------PSVALPV-------AQVPTDPGḦFSVL--------LDVKHFSPEEIAVKVVGEHVEVHARHEERPDEHG 111 HSPB 759 ------HSEPLAFPA-RPGGA----GNIKTLGDAYEFA--------VVDVRF SPEDI IVTTSSNNHIEVRA---EKLAADG 116 HSPB8 67 ---_---GMVPRGPTATARFGVPAEGRTPPPFPGEPWKVC---------VVVVHSFKPEELMVKTKDGYVEVSGKKHEEKQQEGG 134

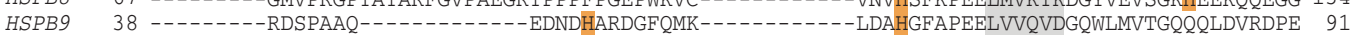
HSPB10 75 LCDYKLYCLRPSLRSLERKAIRAIEDEKRELAKLRRTTNRILASSCCSSNILGSVNVCGFEPDQVKVRVKDGKVCVSAERENRYDCLG 162 Sip1 29 -------HSMLNNFNNIVPQQL----NEVENTAQKFCVK---------LDVAAFKPEELKVNLEGHVLTIEGHHEVK-TEHG 89

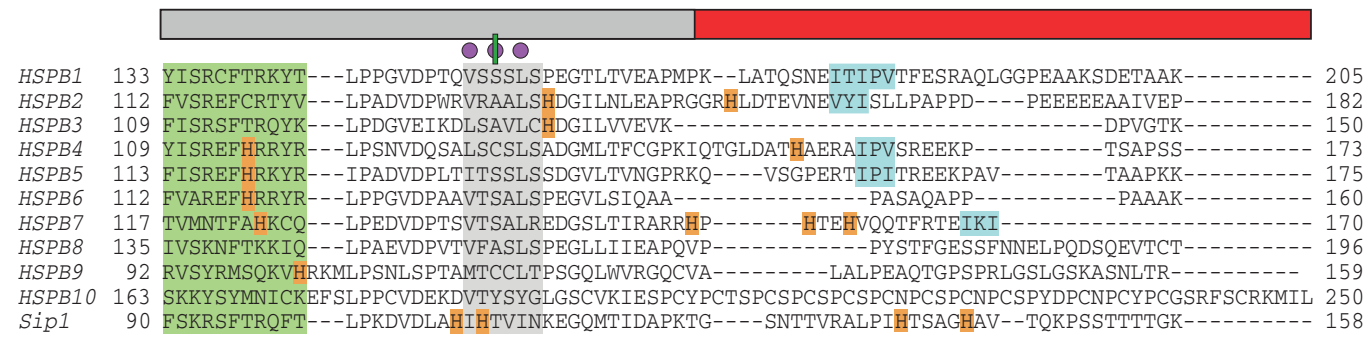

B

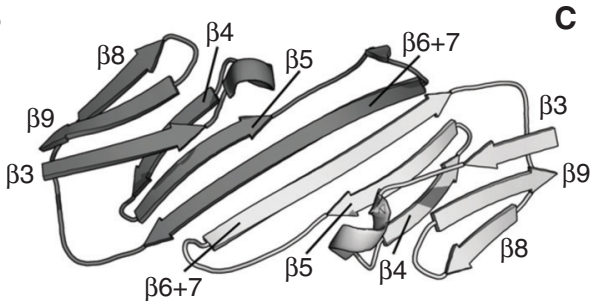

HSPB1: PDB 2N3J

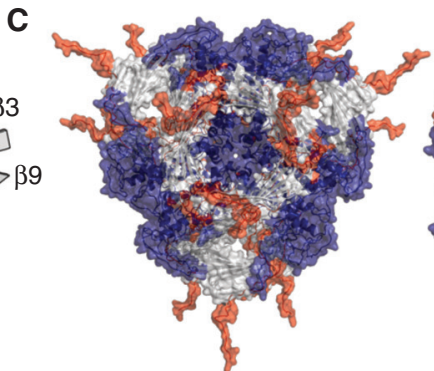

HSPB5: PDB 3J07

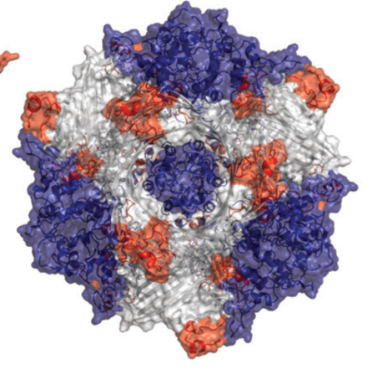

HSPB5: PDB $2 Y G D$

Figure 1. General structural features of small heat shock proteins (sHSPs). (A) Sequence alignment of the 10 human sHSPs and Sip 1, a pH-sensitive sHSP from Caenorhabditis elegans generated with clustal omega and visualized with Jalview. The colored bar above the sequences identify the three regions of sHSPs: amino-terminal region (NTR) (blue), $\alpha$-crystallin domain (ACD) (gray), and carboxy-terminal region (CTR) (red). Important sequence elements are highlighted in different colors: the conserved amino-terminal sequence (yellow), the $\beta 4$ and $\beta 8$ strands that compose the groove (gray), the $\beta 6+7$ strand that makes the dimer interface (green), and aminoand carboxy-terminal I/V-X-I/V motifs (blue). Histidine residues are highlighted in orange. The positions with sidechains pointing into the $\beta 4 / \beta 8$ groove are indicated by purple dots, and the site of the "bump mutation" located in $\beta 8$ is additionally labeled by a green bar crossing the purple dot. (B) ACD architecture. All sHSPs contain a core conserved ACD with an IgG-like $\beta$-sandwich fold. Human ACDs form an antiparallel dimer along the $\beta 6+7$ strand. $(C)$ Oligomeric organization of HSPB5. Two pseudo-atomic models of HSPB5 oligomers generated using a combination of solid-state nuclear magnetic resonanace (NMR), electron microscopy (EM), small-angle X-ray scattering, and structural modeling (left) (Jehle et al. 2011) and NMR, EM, and structural modeling (right) (Braun et al. 2011). Both depict 24-mers with tetrahedral geometry and extensive interactions among the three regions. 
M.K. Janowska et al.

approaches, truncated forms of sHSPs that contain an ACD are amenable to X-ray diffraction and nuclear magnetic resonanace (NMR). A growing database of atomic-level structures of ACDs reveal a common and highly similar subunit fold (Table 2; Fig. 1B). Small differences exist among available structures, but variation in experimental conditions used makes it difficult to draw functional insight from the differences. Nevertheless, clear common features are revealed by these structures. Oligomerization of sHSPs is driven by a hierarchy of interactions. Two subunits form a dimer through their ACD $\beta$-sandwich structures via antiparallel alignment of their long $\beta 6+7$ strands (Fig. 1B). The "bottom slice" of the $\beta$-sandwich is composed of six $\beta$-strands, that is, $\beta 4, \beta 5$, and $\beta 6+7$ from each subunit. Each ACD contains a hydrophobic groove at the opposite edge from the dimer interface formed by a $\beta 4$ strand from the "bottom" sheet and a $\beta 8$ strand from the "top." Many sHSPs contain a three-residue motif known as "I/V-X-I/V" (i.e., isoleucine or valine, followed by any amino acid [usually a proline], followed by isoleucine or valine), in their CTR, and binding of this motif into the $\beta 4-\beta 8$ groove has been observed in crystal structures of HSPB1, HSPB4, and HSPB5 (Table 2; Fig. 2A). In solution, the CTR of HSPB5 exists in equilibrium between ACD-bound and unbound states (Jehle et al. 2011; Baldwin et al. 2012; Delbecq et al. 2012). The CTR/ACD interaction plays an important role in subunit recruitment both in the case of HSPB5 homo-oligomers and HSPB5/HSPB6 hetero-oligomers (Delbecq et al. 2015) and likely in other sHSPs as well. More recently, it has become appreciated that I/V-X-I/V-like sequences appear in many NTRs (Fig. 1A). A crystal structure of an HSPB2/HSPB3 heterotetramer reveals $\mathrm{I} / \mathrm{V}-\mathrm{X}-\mathrm{I} / \mathrm{V}$ motifs in the NTR of HSPB3 and the

Table 2. Mammalian small heat shock protein (sHSP) structures available in the Protein Data Bank (PDB)

\begin{tabular}{|c|c|c|c|c|c|}
\hline PDB ID & Protein & Organism & Method & $\begin{array}{c}\text { Ligand in } \beta 4 / \\
\beta 8 \text { groove? }\end{array}$ & Mutations, notes \\
\hline $2 \mathrm{~N} 3 \mathrm{~J}$ & HSPB1 & Human & snNMR & - & \\
\hline 3Q9P & HSPB1 & Human & X-ray & - & Atypical dimers; EE125/126AA \\
\hline 3Q9Q & HSPB1 & Human & $\mathrm{X}$-ray & - & Atypical dimers; EE125/126AA \\
\hline $4 \mathrm{MJH}$ & HSPB1 & Human & $\mathrm{X}$-ray & Yes & \\
\hline $6 \mathrm{~F} 2 \mathrm{R}$ & HSPB2/HSPB3 & Human & $\mathrm{X}$-ray & Yes & \\
\hline $3 \mathrm{~N} 3 \mathrm{E}$ & HSPB4 & Zebrafish & $\mathrm{X}$-ray & Yes & \\
\hline $3 \mathrm{~L} 1 \mathrm{~F}$ & HSPB4 & Bovine & $\mathrm{X}$-ray & - & \\
\hline 3L1E & HSPB4 & Bovine & X-ray & - & $\mathrm{Zn}^{2+}$-bound \\
\hline $2 \mathrm{KLR}$ & HSPB5 & Human & ssNMR & - & \\
\hline $2 \mathrm{~N} 0 \mathrm{~K}$ & HSPB5 & Human & snNMR & - & N146D \\
\hline 2WJ7 & HSPB5 & Human & X-ray & - & \\
\hline $2 \mathrm{Y} 1 \mathrm{Y}$ & HSPB5 & Human & $\mathrm{X}$-ray & Yes & L137MSE \\
\hline $2 \mathrm{Y} 1 \mathrm{Z}$ & HSPB5 & Human & $\mathrm{X}$-ray & Yes & R120G, L137M \\
\hline $2 \mathrm{Y} 22$ & HSPB5 & Human & X-ray & - & L137MSE \\
\hline 2YGD & HSPB5 & Human & EM & Yes & S65T, Y66W \\
\hline 3J07 & HSPB5 & Human & ssNMR; SAXS; EM & Yes & \\
\hline $3 \mathrm{~L} 1 \mathrm{G}$ & HSPB5 & Human & $\mathrm{X}$-ray & - & \\
\hline $4 \mathrm{M} 5 \mathrm{~S}$ & HSPB5 & Human & $\mathrm{X}$-ray & Yes & \\
\hline $4 \mathrm{M} 5 \mathrm{~T}$ & HSPB5 & Human & X-ray & Yes & E117C \\
\hline 2WJ5 & HSPB6 & Rat & X-ray & - & \\
\hline 4JUS & HSPB6 & Human & $\mathrm{X}$-ray & Yes & \\
\hline 4JUT & HSPB6 & Human & $\mathrm{X}$-ray & Yes & EE104/105AA \\
\hline 5LUM & HSPB6 & Human & X-ray & Yes & \\
\hline 5LTW & HSPB6 & Human & X-ray & Yes & Complex with $14-3-3 / \mathrm{Ni}^{2+}$ bound \\
\hline
\end{tabular}

$\mathrm{X}$-ray, X-ray diffraction; snNMR, solution-state nuclear magnetic resonance; ssNMR, solid-state nuclear magnetic resonance; EM, electron microscopy; SAXS, small-angle X-ray scattering. 
A
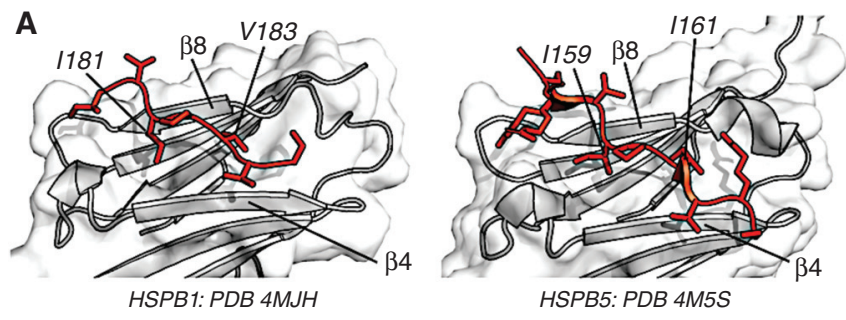

C

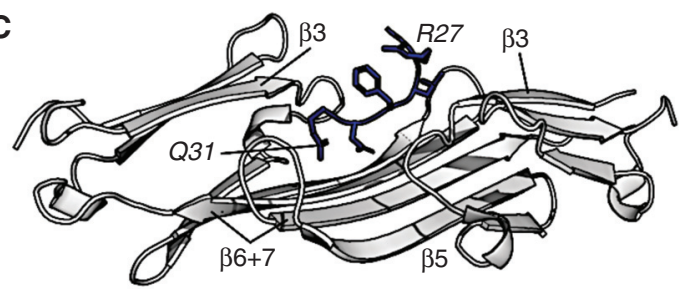

HSPB6: PDB 5LTW

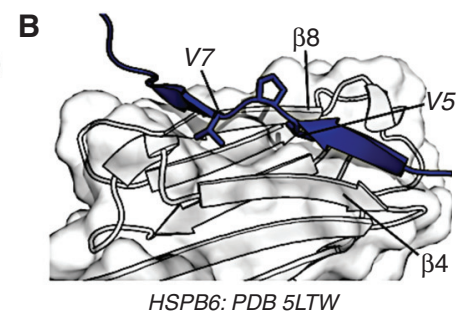

D

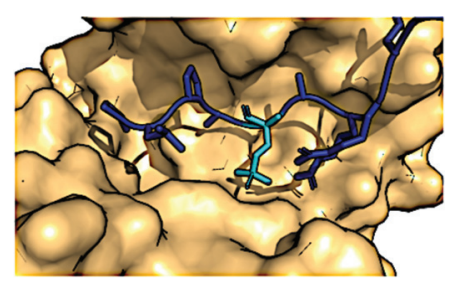

HSPB6: PDB 5LTW

Figure 2. Structural aspects of small heat shock protein (sHSP) assembly. Assembly of sHSP oligomers is driven by interactions that involve all three regions: the $\alpha$-crystallin domain (ACD) (gray), the amino-terminal region (NTR) (blue), and the carboxy-terminal region (CTR) (red). PDB IDs are indicated below each panel. (A) ACD $\beta 4 / \beta 8$ groove interactions with carboxy-terminal I/V-X-I/V motifs. The CTRs of many human sHSPs contain I/V-X-I/V motifs, which can dock into the $\beta 4 / \beta 8$ groove on the outer edge of the ACD. Shown here, HSPB1 and HSPB5 ACDs were crystallized with peptides containing their carboxy-terminal I/V-X-I/V motifs (Hochberg et al. 2014). (B) ACD $\beta 4 / \beta 8$ groove interactions with an amino-terminal I/V-X-I/V motif. Several human sHSPs contain I/V-X-I/V motifs in their NTRs, which can also bind the $\beta 4 / \beta 8$ groove. A crystal structure of full-length HSPB6 revealed its amino-terminal VPV motif bound in the groove (Sluchanko et al. 2017). (C) ACD dimer interface interactions with an NTR sequence. The HSPB6 structure revealed interactions between the conserved NTR sequence ${ }^{27} \mathrm{RLFDQ}^{31}$ and a groove at the dimer interface of the ACD (Sluchanko et al. 2017). (D) Phosphorylation-dependent NTR-client interactions. Phosphorylated Ser16 (teal) in the HSPB6 NTR facilitates interactions with the client protein 14-3-3 (orange). This may serve as a model for other phosphorylationdependent client interactions and provides the only atomic-level information about NTR-client interactions available to date (Sluchanko et al. 2017).

CTR of HSPB2 bound in the $\beta 4-\beta 8$ grooves of different HSPB2 subunits (Clark et al. 2018). An $\mathrm{I} / \mathrm{V}-\mathrm{X}-\mathrm{I} / \mathrm{V}$ motif at the amino-terminal end of HSPB6 is inserted in the groove in a structure of full-length, phosphorylated HSPB6, an sHSP that does not contain an I/V-X-I/V motif in its CTR (Fig. 2B) (Sluchanko et al. 2017). A structure of a truncated form of HSPB6 lacking the NTR I/V-X-I/V motif revealed five ways in which other hydrophobic residues such as leucine and proline in the NTR can insert into the $\beta 4-\beta 8$ groove (Weeks et al. 2014). Although some of the observed interactions may be caused by crystal packing effects, as suggested by the investigators, the observation of knob-and-hole interactions involving noncanonical I/V-X-I/V motifs strongly suggests that we should expand our view of the role of $\beta 4-\beta 8$ groove interactions in oligomerization to include the NTR and relax the definition of the I/V-X-I/V motif.

A structure of full-length HSPB6 revealed another NTR/ACD interaction in which the NTR sequence ${ }^{27}$ RLFDQRFG ${ }^{34}$ binds in a groove formed by the ACD dimer interface (Fig. 2C) (Sluchanko et al. 2017). This NTR sequence is the sole conserved region among human NTRs (Fig. 1A). In light of strong sequence conservation of the dimer interface, it is tempting to predict that other sHSPs may use an analogous NTR-ACD contact. Intriguingly, a recent structure of an HSPB2/HSPB3 heterotetramer shows a fragment docked in the ACD dimer interface groove, but the data do not permit unambiguous assignment of a protein segment to the electron density (Clark et al. 2018). Clarity on this point must await further experimentation and, possi- 
M.K. Janowska et al.

bly, new structures. Models of HSPB5 oligomers based on solid-state NMR and electron microscopy (EM) data depict extensive NTR-NTR interactions between adjacent protomers (Fig. 1C); but these interactions are not well-defined because of the difficulty of characterizing disordered, heterogeneous protein regions (Braun et al. 2011; Jehle et al. 2011).

Conservation of the interaction motifs described above implies that most sHSPs use these types of interactions to achieve their quaternary structures. However, the different oligomeric propensities among human sHSPs suggest that the relative contributions of each type of interaction differ and that structural variability is encoded in each sequence. Furthermore, sHSP oligomeric structures are not static and are exquisitely responsive to environmental conditions, likely through modulation of the interactions and their relative contributions (Jehle et al. 2011; Peschek et al. 2013; Rajagopal et al. 2015b).

Although information on sHSP structures has increased in recent years, progress has been far slower than in most fields in which structural biology has played a role (Table 2). The inherent properties of sHSPs pose substantial challenges to the goal of defining their structures at atomiclevel detail. Indeed, the dynamics and polydispersity displayed by sHSPs beg the question of what it even means to "define" their structure. We are optimistic that emerging approaches including cryoelectron microscopy (cryo-EM), solid-state NMR, and single-molecule techniques have the potential to greatly enhance our understanding of sHSP structures.

\section{Structural Features of sHSP/Client Interactions}

Despite the experimental challenges of defining sHSPs structurally, information regarding client-binding sites is beginning to emerge. A combination of biochemical and structural approaches has proven useful in elucidating the domains and regions involved in chaperone activity. Both the NTR and the ACD have been implicated in client binding and chaperone activity for various $\mathrm{sHSP} /$ client pairs. Using solid- state NMR, Mainz et al. (2015) showed that HSPB5 uses different regions to bind different clients. Lysozyme, which forms amorphous aggregates, is bound by the NTR of HSPB5, and deletion of this domain abolishes HSPB5 chaperone activity toward this client. The amyloid fibril-forming peptide $A \beta 1-40$ binds in the hydrophobic $\beta 4-\beta 8$ groove of HSPB5 ACD, and chaperone activity is retained on deletion of the NTR. An ACD dimer that lacks the NTR and CTR can inhibit aggregation of A $\beta 1-42$, $\alpha$-lactalbumin, and $\kappa$-casein, implying a direct role for this domain in HSPB5 chaperone activity for these clients (Hochberg et al. 2014). However, although the chaperone activity of the ACD matches that of full length HSPB5 in the case of A $\beta 1-42$ and $\alpha$-lactalbumin in this study, it showed diminished chaperone activity against $\kappa$-casein relative to full-length HSPB5, implying that additional regions are involved. Intriguingly, HSPB5 ACD had enhanced chaperone activity relative to full-length HSPB5 toward the clients $\alpha$-synuclein and tau, leading to the proposal that the other domains may inhibit chaperone activity of the ACD (Liu et al. 2018). The HSPB1 NTR is vital for binding T4 lysozyme (McDonald et al. 2012), and the isolated HSPB1 ACD appears unable to bind fibrils composed of the client protein $\alpha$-synuclein (Cox et al. 2018). In the only structure of a full-length sHSP in complex with a binding partner currently available, the NTR of phosphorylated HSPB6 makes direct contact with the signaling protein 14-3-3 (Sluchanko et al. 2017) via a phosphorylated serine in the HSPB6 NTR, which interacts directly with the client (Fig. 2D). In sum, available results implicate both the NTR and ACD in client recognition and chaperone activity, with varying roles that depend on the client protein. To date, the CTR has not been shown to directly interact with any client protein, but its roles in oligomerization and subunit exchange likely contribute to sHSP chaperone activity.

Natively folded proteins may be destabilized by changes in temperature, $\mathrm{pH}$, mutation, oxidative state, or other perturbations. Small changes in cellular environment that cause or signal stress likely lead to partially unfolded, rather than fully unfolded protein states. Such 
states may display increased exposure of hydrophobic residues that are the likely signals for sHSP binding; failure to either refold such regions or engage such regions by sHSPs can lead to protein aggregation. Due to the instability and heterogeneity of such states, determination of recognition motifs within binding partners is challenging. A potential recognition element is the I/V-X-I/V motif-that is, the same motif present in sHSP NTRs and/or CTRs that binds in the $\beta 4-\beta 8$ groove of the ACD. The presence of $\mathrm{I} / \mathrm{V}-\mathrm{X}-\mathrm{I} / \mathrm{V}$-like motifs in putative clients would suggest an interesting possibility of a competition between sHSP subunits and clients for binding to the grooves. As mentioned earlier, the CTR I/V-X-I/V motif of HSPB5 exists in a bound/unbound equilibrium and the populations of the two states are dependent on conditions such as temperature and $\mathrm{pH}$. Therefore, availability of the $\beta 4-\beta 8$ groove for client binding may be modulated by environmental conditions. The client protein tau contains I/V-X-I/V sequences within two aggregation-prone motifs that are recognized by HSPB1 (Baughman et al. 2018). Although the tau-binding site on HSPB1 has not been explicitly determined, it is predicted to be the $\beta 4-\beta 8$ groove. The peptide $A \beta 1-40$ and the protein $\alpha$-synuclein bind in the $\beta 4-\beta 8$ groove of HSPB5 via the sequences LVFFA and DVFMK, respectively (Mainz et al. 2015; Liu et al. 2018). These sequences do not strictly follow the I/V-X-I/V motif, but are enriched in other hydrophobic residues, lending further support for the notion that the definition of $\beta 4-\beta 8$ groovebinding sequences should be expanded to include other hydrophobic residues. Nonclient sHSPbinding partner and HSP70 cochaperone BAG3 also binds in the groove (Rauch et al. 2017), providing an additional level of potential competitive binding among cellular proteins.

The prevalence of I/V-X-I/V-like motifs and their predilection to bind to $\beta 4-\beta 8$ grooves of sHSP ACDs raises the important question of whether an observed interaction is functionally relevant or serendipitous. Structure-based mutations can be used to parse out this key question. The "groove bump" mutation, S135Q in HSPB5, blocks binding of the CTR I/V-X-I/V motif of HSPB5 to the $\beta 4-\beta 8$ groove (Delbecq et al.
2012) and likely blocks other $\beta 4-\beta 8$ interactions, although these have been less well-studied to date. The groove bump mutation enhances HSPB5 chaperone activity against $A \beta 1-40$, which the investigators attributed to reduced competition with the CTR motif (Mainz et al. 2015), although how this mutation affects client binding and the relative affinities of the client protein, the NTR, and the CTR for the $\beta 4-\beta 8$ groove remain to be determined. The position analogous to S135 in HSPB5 is conserved as a small sidechain in all human sHSPs, so analogous bump mutations can easily be designed for other systems (Fig. 1). "GXG" mutations in the CTR of HSPB5 and HSPB1 have been used to eliminate the $\mathrm{I} / \mathrm{V}-\mathrm{X}-\mathrm{I} / \mathrm{V}$ motif from these regions by mutating the isoleucine and valine residues to glycine, such that the motif no longer binds the groove (Delbecq et al. 2012). These and analogous mutations in other sHSPs will enable the importance of CTR/client competition to be assessed.

Despite its clear implication in client binding, details regarding potential recognition elements within the NTR are almost completely lacking. Whether sHSPs recognize sequence features beyond exposed hydrophobic residues, whether there are differences between sequences bound by the ACD and by the NTR, and how the interactions function to delay protein aggregation are questions for the future.

\section{sHSP FUNCTION}

sHSPs are best known as early responders to cellular stress that delay the onset of irreversible protein aggregation. They are also implicated in a growing number of other processes including cellular signaling and regulation of apoptosis. How and whether the chaperone and nonchaperone activities are related is an open question. Given the diversity in human sHSP sequence, oligomerization, and tissue distribution, it is likely that different sHSPs have evolved to respond to specific forms of stress experienced in different tissue types (Table 1). For example, cardiac muscle is subject to chronic stress from contraction and may also be subjected to acute stress conditions in pathological or disease conditions (Lomiwes et al. 2014). Whether the same 
M.K. Janowska et al.

sHSPs are responsible for both chronic and acute stress responses is as yet unknown.

\section{Constitutive Roles of sHSPs}

Constitutive roles for sHSPs include regulation of cytoskeletal elements, cell signaling, and maintenance of eye lens transparency and refractive properties (Dubińska-Magiera et al. 2014; Bakthisaran et al. 2015; Carra et al. 2017). To illustrate the diverse roles of sHSPs, we discuss sHSP function in the eye lens and muscle tissue.

The eye lens is a specialized structure that transmits and focuses light on the retina. Transparency and absence of light diffraction is achieved by the removal of all subcellular structures, including the nucleus from lens fiber cells, creating cells with minimal protein turnover ability. This situation imposes a strong requirement for protective mechanisms in these cells as the ability to dispose of misfolded and damaged proteins is reduced and the ability to synthesize new ones does not exist (Pereira et al. 2003; Lynnerup et al. 2008). Lens proteins are susceptible to damage caused by ultraviolet (UV) light and oxidative stress, both of which lead to chemical modifications, yet, lens proteins must be maintained in soluble forms throughout the life of an individual to avoid formation of insoluble protein aggregates (i.e., lens cataract) (Michael and Bron 2011; Yanshole et al. 2013; Srivastava et al. 2017). Two members of the sHSP family, HSPB4 and HSPB5 (also known as $\alpha$-crystallins), are responsible for this critical function. HSPB4 and HSPB5 account for $40 \%$ of the total protein content in the lens, where they exist as soluble oligomers at concentrations above $150 \mathrm{mg} / \mathrm{mL}$ (Bloemendal 1977). Weak interactions with other crystallin proteins facilitate uniform protein distribution in the lens, yielding a transparent, highly refractive lens necessary for proper vision (Fu and Liang 2002; Takemoto and Sorensen 2008). The lens sHSPs serve additional functions through interactions with cytoskeletal proteins such as actin and intermediate filaments such as vimentin, filensin, and phakinin (Nicholl and Quinlan 1994; Muchowski et al. 1999; Andley et al. 2014; Cheng et al. 2017). Disease-related mutations in HSPB4 and HSPB5 affect binding to the cytoskeleton, implying the importance of these interactions (Andley et al. 2014). Lens sHSPs also protect against UV-A radiation and regulate apoptosis through signaling. On UV-A stress, HSPB4 activates the Akt antiapoptotic pathway and HSPB5 prevents activation of the RAF/MEK/ ERK pathway (Liu et al. 2004). Thus, even in a tissue as seemingly simple as the eye lens, sHSPs fulfill both chaperoning and nonchaperoning functions.

sHSPs also play constitutive and stress-induced roles in cardiac and skeletal muscles. Functional myofibrils require systematic and controlled movements of cytoskeletal elements for muscle contraction. Muscles are subject to high oxidative stress conditions in their normal working modes so it is perhaps not surprising that many sHSPs are expressed at high level in different types of muscle tissue: HSPB1, HSPB2, HSPB3, HSPB5, HSPB6, HSPB7, and HSPB8 (Beall et al. 1997; Sugiyama et al. 2000; Kappé et al. 2001). Specific muscle sHSPs may partly or fully diverge in function. For example, HSPB7 has a role in maintaining myofiber structure and intercalated disc integrity but shows no protection against protein aggregation in cell lysate experiments (Wales et al. 2016; Liao et al. 2017; Mymrikov et al. 2017). An emerging area of investigation is a role for sHSPs in the maintenance of cytoskeletal integrity through interactions with muscle proteins, including titin, desmin, actin, and 14-3-3 (Mounier and Arrigo 2002; Houck et al. 2011; Diokmetzidou et al. 2016; Sluchanko et al. 2017; Unger et al. 2017). sHSPs also act as antiapoptosis regulators and protect mitochondria against stress in muscle cells (Garrido et al. 1999; Kamradt et al. 2002; Morrison et al. 2003; Fan 2005; Maloyan 2005; Havasi et al. 2008). The growing list of processes in which sHSPs are directly involved implies that they are responsible for a broad range of protective mechanisms that are central to proteostasis.

\section{Stress-Related Role of sHSP: Mechanisms of Activation}

To fulfill their protective function of delaying the onset of irreversible protein aggregation, 
sHSPs must be highly sensitive to small environmental changes and must respond quickly. Human body temperature is strongly regulated within a few degrees Celsius at most, and as little as a $0.1 \mathrm{pH}$ unit change in $\mathrm{pH}$ is considered acidosis or alkalosis (Juel 2008). The most extreme acidotic $\mathrm{pH}$ change in exercising muscle is less than $1 \mathrm{pH}$ unit, from $\mathrm{pH} 7.4$ to 6.5 (on average, pH 6.9 constitutes acute muscle acidosis) (Carter et al. 1967; Wray 1988; Street et al. 2001). Here, we will discuss activation mechanisms of sHSPs in response to cellular conditions.

\section{Thermal Activation}

As their name suggests, sHSPs are activated by elevated temperature. However, what constitutes heat shock differs among organisms, and different sHSPs are activated in different temperature ranges depending on their environment or body temperature (Haslbeck and Vierling 2015). HSP16.5 from hyperthermophiles is activated between $60^{\circ} \mathrm{C}$ and $95^{\circ} \mathrm{C}$ (Bova et al. 2002), although activation temperature of the lens-specific HSPB4 in fish depends on the habitat water temperature (Posner et al. 2012). In temperatures normal for yeast $\left(25^{\circ} \mathrm{C}\right), \mathrm{S}$. cerevisiae HSP26 is inactive and only shows chaperone function with increased temperature (Haslbeck et al. 1999). Although temperaturedependent sHSP activity is well documented, the structural basis for enhanced activity remain poorly understood. A small transition is detected by differential scanning calorimetry at near physiological temperatures $\left(37^{\circ} \mathrm{C}-45^{\circ} \mathrm{C}\right)$ for bovine HSPB4 and HSPB5 purified from lens cells, suggesting that mammalian sHSPs undergo some sort of structural alteration near physiological temperatures (Walsh et al. 1991). Altogether it is clear that sHSPs have evolved to be sensitive to small changes in temperature near physiological temperature.

\section{pH Activation}

In mammals, even small variations in cellular $\mathrm{pH}$ can have grave consequences (Krieg et al. 2014). Furthermore, changes in cellular $\mathrm{pH}$ are associated with some disease states. In tumor development, intracellular $\mathrm{pH}$ is increased and extracellular $\mathrm{pH}$ is decreased (Shirmanova et al. 2015; Huber et al. 2017). Acidification of brain tissue as a function of aging and in Alzheimer's and Parkinson's disease patients has been reported (Forester et al. 2009; Henderson et al. 2014; Hu et al. 2015; Majdi et al. 2016). A decrease in $\mathrm{pH}$ is also found in ischemic tissues with restricted blood supply (e.g., brain, heart, and kidneys) (Marzouk et al. 2002; McVicar et al. 2014; Longo et al. 2017). sHSPs are activated by ischemic conditions (Martin et al. 1997; Stetler et al. 2012; Sharp et al. 2013). Lens cells that depend on the activity of their high constitutive levels of HSPB4 and HSPB5 have a normal $\mathrm{pH}$ of $\sim 6.5$, implying that these sHSPs are active at the low end of the physiological $\mathrm{pH}$ range (Bassnett and Duncan 1985). Thus, analogous to their high sensitivity to small temperature changes, the sHSPs have evolved to respond to small changes in $\mathrm{pH}$.

Histidine (His) residues are the likely key to $\mathrm{pH}$ modulation of sHSPs as the $\mathrm{pKa}$ of His sidechains make them well suited to respond in the relevant $\mathrm{pH}$ range of 6.4-7.5. HSPB2-7 are enriched in histidines, especially within their ACDs, containing more than twice the average across all proteomes (Fig. 1A) (Moura et al. 2013). At pH 6.5, HSPB5 forms expanded oligomers by a rearrangement that is dictated by a single histidine residue (His104) (Rajagopal et al. 2015b). Paradoxically, oligomeric expansion at pH 6.5 is linked to destabilization of the ACD dimer interface. A mutant that mimics the protonated His104 state, H104K-HSPB5, yields HSPB5 that displays low $\mathrm{pH}$ properties (expanded oligomers and enhanced chaperone activity) at $\mathrm{pH}$ 7.5. Histidine is conserved at the analogous position in seven of ten human sHSPs (Fig. 1A). HSPB1 shows similar $\mathrm{pH}$ behavior to HSPB5 and the corresponding His 124 also acts as an activation switch. The effect of $\mathrm{pH}$ on HSPB1 is more modest than in HSPB5, highlighting the diversity in function and stress response of sHSPs (Clouser and Klevit 2017). $\mathrm{pH}$ activation has also been shown for an sHSP from C. elegans, Sip1 (Fleckenstein et al. 2015). Intriguingly, some Sip1 histidines, including the 
M.K. Janowska et al.

position corresponding to His104 in human HSPB5, align with those in human sHSPs, but $\mathrm{pH}$ has the opposite effect on oligomeric ensemble size, with Sip1 oligomeric size decreasing with decreasing $\mathrm{pH}$ (Fig. 1A). These observations suggest that the $\mathrm{pH}$ activation mechanism of sHSPs may use similar residues (primary/ secondary structure), but with structurally divergent ramifications at the level of higher order organization. A more complete understanding of sHSP $\mathrm{pH}$ activation will require additional studies on other members of the family.

\section{Oxidative Stress and Metals}

Oxidative stress occurs when reactive oxygen species (ROS) formed in cells fail to be properly neutralized. This situation can occur from normal processes as well as pathological situations such as bacterial infection or exposure to metals (Finkel 2011; Sies et al. 2017). Among the groups targeted by ROS are oxidation-sensitive amino acid residues in proteins whose modification can cause changes in protein structure that can affect function and/or lead to aggregation (Reichmann et al. 2018). Surprisingly, little is known about the role of sHSPs in cell protection under oxidative stress. HSPB1 and HSPB5 are proposed to be modulators of glutathione levels and to be protective against oxidative stress in cell lines (Préville et al. 1999; Arrigo et al. 2005; Christopher et al. 2014). HSPB4 and HSPB5 protect against oxidative stress in the eye lens (Wang and Spector 1995). Structural and mechanistic information on sHSPs under oxidative stress is lacking. An oxidation-sensitive cysteine located at the center of the HSPB1 dimer interface may govern monomer-dimer exchange (Rajagopal et al. 2015a). Although a role for sHSPs in oxidative stress mitigation seems sensible, strong and compelling evidence in support of this putative role remains missing.

Metal ions mediate many cellular processes, including oxygen utilization, immunological system response, and enzymatic activities (Bleackley and MacGillivray 2011). Cellular metal concentrations are tightly regulated: Accumulation of a given metal outside its functional concentration range can be toxic and is implicated in many diseases (Jomova and Valko 2011; Jaishankar et al. 2014). Changes at the level of intracellular metal localization, rather than total metal concentration may also be important. Dysregulation of metal homeostasis is linked to oxidative stress, as accumulation of metals facilitates formation of free radicals (Jaishankar et al. 2014). Comprehensive information about the response of sHSPs to metals is not yet available but it is known that certain metals can induce expression of some sHSPs. For example, $\mathrm{Cu}^{2+}$ and $\mathrm{Cd}^{2+}$ increase expression of sHSPs in human epithelial cells transformed into lens fibers (Ganadu et al. 2004). Exposure to $\mathrm{Cd}^{2+}$ affects the expression level of sHSPs in aquatic midges (Martín-Folgar and Martínez-Guitarte 2017). In response to $\mathrm{As}^{3+}$ exposure, HSPB1 expression was decreased via tumor suppressor p27 (Liu et al. 2010). Biochemically, HSPB1, HSPB4, and HSPB5 bind $\mathrm{Cu}^{2+}$ with picomolar affinity, and a single HSPB5 oligomer can reportedly sequester up to $150 \mathrm{Cu}^{2+}$ ions, acting as an ion "sponge" (Prabhu et al. 2011; Mainz et al. 2012). $\mathrm{Cu}^{2+}$ binding by the HSPB5 ACD is reported to affect monomer-dimer equilibrium, which in turn promotes formation of larger oligomers (Mainz et al. 2012). The link between ACD dimer interface stability and oligomer size is reminiscent of that observed for the $\mathrm{pH}$ effect in HSPB5 and may point to shared or overlapping effects of $\mathrm{pH}$ and metal ions. $\mathrm{Zn}^{2+}$ is also reported to affect sHSP ensembles (Ganadu et al. 2004; Biswas and Das 2008; Karmakar and Das 2011). In contrast to other heavy metals, zinc counteracts oxidative stress. Currently, there appears to be conflicting information regarding the role of zinc in the eye lens. Zinc has been shown to induce aggregation of another lens protein, $\gamma \mathrm{D}$ crystallin, and zinc levels in cataractous lenses are increased despite studies suggesting that zinc supplementation may protect against cataract development (Ketola 1979; Ciaralli et al. 2001; Dawczynski et al. 2002; Quintanar et al. 2016; Domínguez-Calva et al. 2018). Similar to the effects of $\mathrm{Cu}^{2+}, \mathrm{Zn}^{2+}$ alters HSPB5 oligomer organization, stability, and chaperone function (Prabhu et al. 2011; Biswas et al. 2016). The proposed binding site for $\mathrm{Zn}^{2+}$ is located within the ACD (Mainz et al. 
2012). The $\mathrm{pH}$ and metal ion effects described to date suggest that the ACD is responsible not only for forming the dimeric building block of oligomers, but also in controlling oligomeric size and dynamics in ways yet to be fully defined.

\section{Phosphorylation}

In addition to the direct structural and functional responses of sHSPs to cellular conditions, their activity is regulated by phosphorylation. Phosphorylation of sHSPs has been implicated in the regulation of multiple cellular functions including apoptosis, cytoskeletal modulation, cell-cycle regulation, ligand binding, and chaperone activity and is implicated in disease conditions. Hyperphosphorylated HSPB1 is found with tau in neurofibrillary tangles and hyperphosphorylated HSPB5 mutant, R120G, accumulates in insoluble fractions (Nemes et al. 2004; Shimura et al. 2004; Bakthisaran et al. 2016). The kinases involved in sHSP regulation are known in some instances, but detailed information about all possible players in the regulation of sHSPs is yet to be determined. Most phosphorylation sites identified in sHSPs are localized in the disordered NTR where the modification likely exposes binding sites that provide enhanced chaperone activity and additional homeostatic functions. There are three sites in the NTRs of HSPB1 and HSPB5 (15, 78, and 82 and 19,45 , and 59, respectively). Phosphorylation is often mimicked experimentally by substitution of the serine residues that are phosphorylated with negatively charged aspartate or glutamate. Studies on phosphorylated or phosphomimics of HSPB1 and HSPB5 reveal a substantial decrease in the average oligomer size relative to unphosphorylated protein, with fully phosphorylated species existing predominantly as dimers or tetramers of HSPB1 or 6-mers and 12-mers of HSPB5 (Rogalla et al. 1999; Peschek et al. 2013; Jovcevski et al. 2015). In most but not all instances, phosphorylation (or its mimicry) is associated with an increase in chaperone activity toward clients (Koteiche and McHaourab 2003; Shashidharamurthy et al. 2005; Meehan et al. 2007; Ahmed et al. 2009; Hayes et al. 2009; Peschek et al. 2013; Jovcevski et al. 2015). HSPB5 phosphomimics show decreased chaperone activity toward $\operatorname{cc} \beta$-Trp, luciferase, and $\mathrm{LDH}$, and phospho-HSPB1 has decreased activity toward citrate synthase (Rogalla et al. 1999; Ito et al. 2001; Ecroyd et al. 2007). Moreover, it appears that the extent of phosphorylation is important: A single phosphomimicking mutation in HSPB5 shows antiapoptotic activity (inhibition of caspase-3), although the triple phosphomimic does not (Morrison et al. 2003).

In summary, sHSPs are highly sensitive to small changes in cellular environment and can respond rapidly to change. Changes in conditions such as $\mathrm{pH}$, temperature, and metal binding bring about changes in sHSP structure and, therefore, activity. Their adaptability is mediated through hierarchical structural organization and, possibly, changes in their dynamics that involve both ordered and disordered regions of sHSPs. However, although a boon to their cellular functions, the intrinsic plasticity of sHSPs render their rigorous study challenging, as small alterations in experimental conditions can have profound effects on their properties and function.

\section{MECHANISMS OF CLIENT INTERACTIONS}

A central question in the sHSP field is: How are clients recognized and engaged? Historically, studies have tended to use model client proteins such as $\alpha$-lactalbumin and $\kappa$-casein, as they provide experimentally tractable systems (Ecroyd et al. 2007; Kulig and Ecroyd 2012). More recently, bona fide clients known to aggregate within the cell, such as the amyloid-forming proteins tau, $A \beta$, and $\alpha$-synuclein, and metabolic enzymes that form amorphous aggregates under destabilizing conditions have been investigated (Mainz et al. 2015; Cox et al. 2016; Mymrikov et al. 2017; Baughman et al. 2018; Liu et al. 2018). Important open questions include what regions of sHSPs are involved in client binding and chaperone activity, are there common features in clients that enable sHSP recognition, what types of client/sHSP complexes are formed and what are the species of aggregation-prone clients that are effectively engaged by the sHSP, and how do sHSP oligomerization and subunit exchange dynamics relate to chap- 
M.K. Janowska et al.

erone activity. The current state of knowledge regarding the nature and identity of sHSP/client interaction sites was presented in the section on Structural Features of sHSP/Client Interactions. Below, we review information relevant to the other questions posed.

It is becoming clear that the types of sHSP/ client complexes formed vary considerably depending on the sHSP, the client, the conditions, and the client aggregation pathway and type of aggregate formed. HSPB5 and HSPB1 interact weakly and transiently with the clients $A \beta$, tau, and $\alpha$-synuclein, as evidenced by the inability to detect complexes by NMR or size-exclusion chromatography (Mainz et al. 2015; Cox et al. 2016; Baughman et al. 2018). Notably, these clients are intrinsically disordered in solution and form amyloid fibrillar aggregates. In contrast, when presented with $\alpha$-synuclein fibrils, HSPB1 was shown to form a tight complex with mature fibrils but not with prefibrillar species (Cox et al. 2018). Similarly, HSPB5 coprecipitates with aggregated lysozyme, which forms amorphous aggregates (Mainz et al. 2015). To test whether HSPB5 interacts differently with an amyloid-forming versus amorphously aggregating client, Kulig and Ecroyd (2012) investigated the mechanisms by which HSPB5 inhibits amorphous aggregation of reduced $\alpha$-lactalbumin and amyloid formation of reduced and carboxymethylated $\alpha$-lactalbumin under otherwise-similar experimental conditions. They found that HSPB5 forms a stable complex with $\alpha$-lactalbumin under conditions that promote its amorphous aggregation but interacts only transiently with $\alpha$-lactalbumin to delay the onset of amyloid formation. Although it is tempting to generalize these observations to suggest that chaperone activity against amyloid-forming clients occur via transient interactions, whereas sHSPs delay formation of amorphous aggregates by forming more stable complexes, it is unlikely that this simple relationship will hold once more data are in hand.

Another emerging theme is that different sHSPs may interact with the same client protein through distinct mechanisms. Mymrikov et al. (2017) showed that different human sHSPs display differential activities against various client proteins, emphasizing the sensitivity of results to the specific sHSP/client pair studied and the perils of attempting to generalize results. As already mentioned, further complications arise from the sensitivity of sHSP structure and function to environmental conditions such as $\mathrm{pH}$ and temperature. Two additional confounding issues are raised by the fact that sHSPs can associate with each other and exist as hetero-oligomeric species in cellular contexts and that sHSPs are not presented with one pure client under cellular stress situations, but rather must engage and delay aggregation for many cellular proteins simultaneously. These important issues remain to be addressed in the future.

The oligomeric state of sHSP/client complexes and the rate at which subunits exchange in and out of oligomers also influence chaperone activity, but there is no consensus on the role of these factors. Some have argued that the chaperone-active sHSP species are small oligomers or dimers, and that reduced oligomeric size and rapid subunit exchange of these species enables enhanced chaperone activity (Peschek et al. 2013; Jovcevski et al. 2015). However, others have documented diminished chaperone activity from phosphorylated sHSPs that form small oligomers and have argued that larger oligomers are the chaperone-active species (Rogalla et al. 1999). Again, the specific effect is likely dependent on the sHSP/client pair studied and the conditions under which chaperone activity is assessed. For example, under acidosis conditions, HSPB5 forms enlarged oligomers. A low pH-mimicking mutation H104K-HSPB5, forms similarly enlarged oligomers under "normal" $\mathrm{pH}$ conditions and has enhanced chaperone activity toward destabilized $\alpha$-lactalbumin (Rajagopal et al. 2015b). Although the wild-type (unactivated) HSPB5 interacts with the clients via only weak, transient interactions, the activated form disassembles into smaller species that coelute with client on size exclusion chromatography. Thus, the precise details of how a given client's aggregation is delayed by an sHSP is a complicated and interconnected process in which factors such as oligomerization and subunit exchange dynamics, binding site accessibility, affinity for client protein, mechanism of 
aggregation and the nature of client species formed along the pathway all contribute (depicted in Fig. 3). This likely gives rise to the enormous diversity and adaptability of sHSP function, but also makes it nearly impossible to determine the influence each has on chaperone activity independently of other factors.

In summary, recent studies have revealed ways in which sHSPs accomplish chaperone activity. The mechanisms of action documented thus far depend on the specific sHSP/client pair under consideration and on the client's mechanism of aggregation, suggesting that sHSP chaperone activity may not be fully described by a single unified model. Rather, it highlights the breadth of function present within this class of chaperones as they target diverse cellular clients.

\section{EXPERIMENTAL CHALLENGES AND THE FUTURE}

Much of our current understanding of the mechanisms of sHSP chaperone function is based on in vitro assessment of function using client proteins that can be selectively destabilized to produce aggregates (Fig. 3). Two overarching goals of in vitro assessment of sHSPs are to (1) determine "all" underlying mechanisms by which sHSPs function, and (2) define "specific" mechanisms by which a given sHSP works with a specific client. Both are important and these two goals require different approaches. The workhorse experiment of in vitro chaperone studies is the aggregation assay in which the effect of presence or absence of an sHSP on a client aggregation time course is assessed. Clients differ in their requirements for destabilization and aggregate morphology. Aggregation of commonly used model clients such as $\alpha$-lactalbumin, lysozyme, and $\beta$-crystallin is initiated by reduction and/or increased temperature. The appearance of aggregates is most often monitored by measuring light scattering, usually detected as increased absorbance of light at $360 \mathrm{~nm}$ $\left(\mathrm{A} 360_{\mathrm{nm}}\right)$, as a function of time. Aggregation of clients that form amyloid-type fibrils such as tau is typically monitored by thioflavin T fluorescence (Biancalana and Koide 2010). Overall, these standard aggregation assays provide a simple way to assess the ability of an sHSP to delay the onset of and/or inhibit aggregation, but there are important limitations. In particular, the strength of the light-scattering signal is a function of both the size and amount of aggregates being formed (Den Engelsman et al. 2011), although thioflavin $\mathrm{T}$ fluorescence is sensitive to both fibril mass and morphology (Lindberg et al. 2015) - a complication further confounded by the fact that these properties will be changing with time and may be dependent on differences in salt, $\mathrm{pH}$, temperature, or other conditions. Therefore, while standard aggregation assays are both widely performed and extremely informative, they are best used as qualitative and comparative assessments of chaperone activity. That said, they are the most robust and most experimentally accessible approach for assessing sHSP chaperone activity in vitro. Studies aimed at characterizing effects of a perturbation (mutation, change in environmental condition, etc.) on sHSP function will benefit from the use of multiple client proteins, and use of uniform experimental conditions.

A study in which chaperone activity of all ten human sHSPs was assessed with several different model clients under different destabilization conditions provides both valuable information and a cautionary tale regarding the level of control required to carry out experiments that can be compared across systems (Mymrikov et al. 2017). Not only were differences in activity toward a given client observed among sHSPs, but differences in client aggregation that depend on solution conditions were also observed. This important study emphasizes the hazards of drawing general conclusions on sHSP function based on the use of a single client or experimental condition and adds an additional level of complexity to efforts to translate in vitro findings on sHSP function to a cellular setting. Thus, while model clients such as $\alpha$-lactalbumin have and will continue to provide important insights into fundamental aspects of sHSP activity, identification and characterization of bona fide cellular clients are important directions for the future. In addition, assessment of sHSP properties such as oligomer size and distribution, subunit exchange 
M.K. Janowska et al.

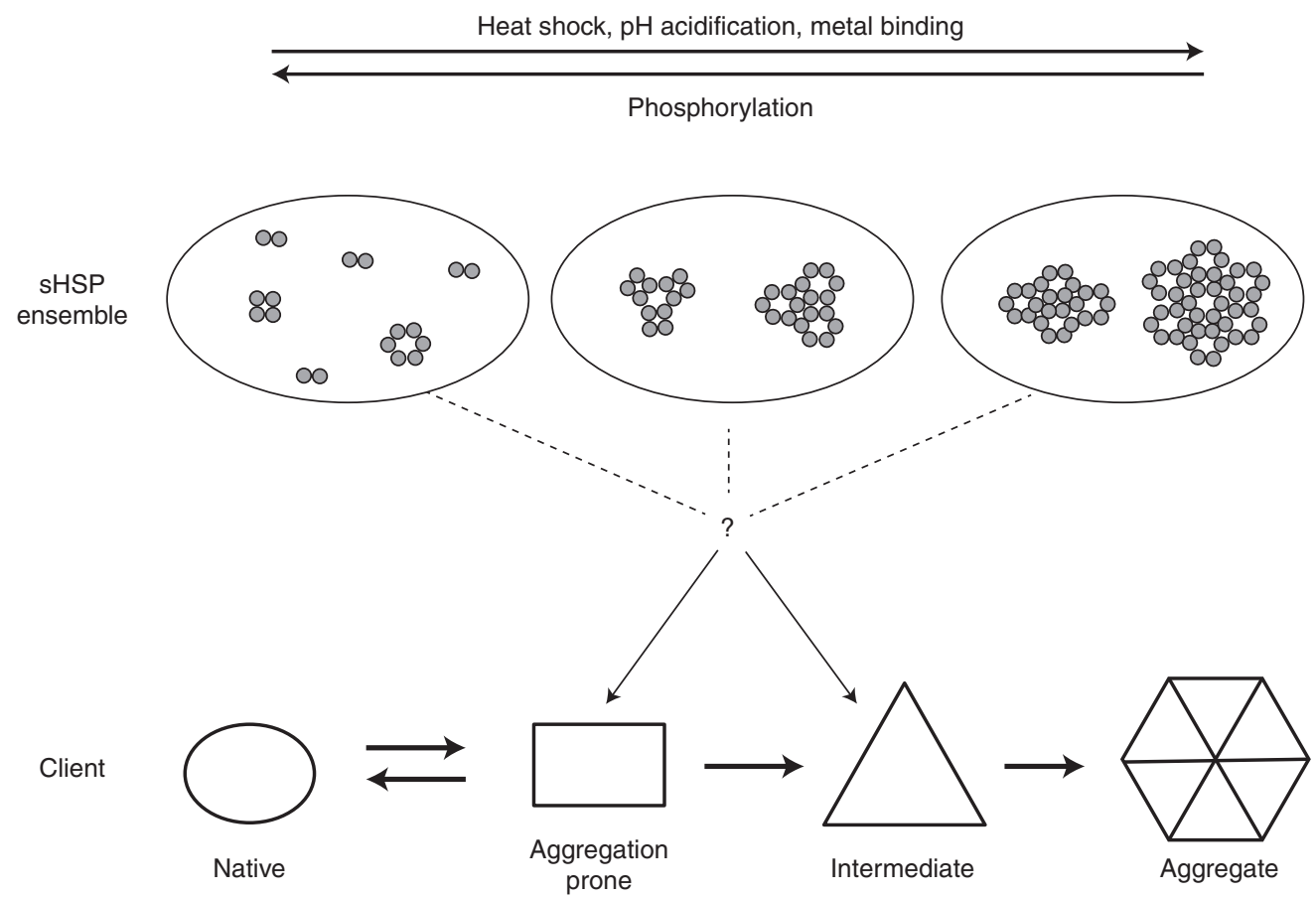

Figure 3. Diversity of small heat shock protein (sHSP) chaperone mechanisms. Many human sHSPs form polydisperse oligomers whose average number of subunits is sensitive to solution conditions or posttranslational modifications. Client aggregation is also sensitive to solution conditions and can potentially affect the client states recognized by an sHSP. It is unknown whether all subunits within a given sHSP ensemble are chaperone active. Many open questions remain, including: (1) Which client states and features of clients do sHSPs recognize? (2) Do different sHSP ensemble sizes recognize different client states and therefore have different chaperone activity? The answers to these and other questions likely depend on sHSPs and client identities and the solution conditions used to assess chaperone function.

rate, time required for an $\mathrm{sHSP}$ to equilibrate to a given condition, availability of client binding surfaces, and dynamics under the chosen experimental conditions will greatly improve our ability to interpret the results. As the biochemical understanding of sHSP function progresses, experimental designs that aim for more "cell-like" conditions are needed. These could include mixtures of sHSPs in ratios that reflect those in a given cell. Of course, even this "simple" parameter is likely to depend on both cell type and cell conditions. Similarly, increasing the complexity of the "client" from a single, purified (model) client protein to mixtures or to cell lysates could provide additional layers of insight.

Despite progress made over the past several decades, we believe that sHSP research is still in its infancy. These fascinating proteins have mostly defied biochemical and structural analysis for reasons discussed above and this has, in turn, slowed progress in understanding the molecular and cellular biology of sHSPs. As structure-based and mechanism-based sHSP mutants are developed (e.g., the groove-bump mutant discussed earlier), these will provide powerful tools with which to investigate the mechanisms of action of sHSPs in cells. Furthermore, emerging technological advances and approaches more suited to dynamic heterogeneous systems promise to be transformational to the field. Application of hydrogen-deuterium exchange, single-molecule approaches, native mass spectrometry, cryoEM, and solid- and solution-state NMR afford exciting possibilities. Coupled with cellular ap- 
proaches that include CRISPR gene-editing and superresolution microscopy, we predict that understanding of how sHSPs work and the consequences of their dysfunction on cellular and organismal health will be fully appreciated at last.

\section{REFERENCES}

Ahmed MH, El Leithy BM, Thompson JR, Flower RJ, Ramdani M, Ayache F, Hassan SM. 2009. Application of remote sensing to site characterisation and environmental change analysis of North African coastal lagoons. Hydrobiologia 622: 147-171. doi:10.1007/s10750-008-9682-8

Andley UP, Malone JP, Townsend RR. 2014. In vivo substrates of the lens molecular chaperones $\alpha \mathrm{A}$-crystallin and aB-crystallin. PLoS ONE 9: e95507. doi:10.1371/journal .pone.0095507

Aquilina JA, Benesch JLP, Bateman OA, Slingsby C, Robinson CV. 2003. Polydispersity of a mammalian chaperone: Mass spectrometry reveals the population of oligomers in aB-crystallin. Proc Natl Acad Sci 100: 10611-10616. doi:10.1073/pnas.1932958100

Arrigo A-P, Virot S, Chaufour S, Firdaus W, Kretz-Remy C, Diaz-Latoud C. 2005. Hsp27 consolidates intracellular redox homeostasis by upholding glutathione in its reduced form and by decreasing iron intracellular levels. Antioxid Redox Signal 7: 414-422. doi:10.1089/ars.2005.7.414

Bakthisaran R, Tangirala R, Rao CM. 2015. Small heat shock proteins: Role in cellular functions and pathology. Biochim Biophys Acta 1854: 291-319. doi:10.1016/j .bbapap.2014.12.019

Bakthisaran R, Akula KK, Tangirala R, Rao CM. 2016. Phosphorylation of $\alpha \mathrm{B}$-crystallin: Role in stress, aging and patho-physiological conditions. Biochim Biophys Acta 1860: 167-182. doi:10.1016/j.bbagen.2015.09.017

Baldwin AJ, Walsh P, Hansen DF, Hilton GR, Benesch JLP, Sharpe S, Kay LE. 2012. Probing dynamic conformations of the high-molecular-weight $\alpha \mathrm{B}$-crystallin heat shock protein ensemble by NMR spectroscopy. J Am Chem Soc 134: 15343-15350. doi:10.1021/ja307874r

Bassnett S, Duncan G. 1985. Direct measurement of $\mathrm{pH}$ in the rat lens by ion-sensitive microelectrodes. Exp Eye Res 40: 585-590. doi:10.1016/0014-4835(85)90080-6

Baughman HER, Clouser AF, Klevit RE, Nath A. 2018. HspB1 and Hsc70 chaperones engage distinct tau species and have different inhibitory effects on amyloid formation. J Biol Chem 293: 2687-2700. doi:10.1074/jbc .M117.803411

Beall AC, Kato K, Goldenring JR, Rasmussen H, Brophy CM. 1997. Cyclic nucleotide-dependent vasorelaxation is as sociated with the phosphorylation of a small heat shockrelated protein. J Biol Chem 272: 11283-11287. doi:10 $.1074 / \mathrm{jbc} .272 .17 .11283$

Biancalana M, Koide S. 2010. Molecular mechanism of thioflavin-T binding to amyloid fibrils. Biochim Biophys Acta 1804: 1405-1412. doi:10.1016/j.bbapap.2010.04.001

Biswas A, Das KP. 2008. $\mathrm{Zn}^{2+}$ enhances the molecular chaperone function and stability of $\alpha$-crystallin. Biochemistry 47: 804-816. doi:10.1021/bi7011965
Biswas A, Karmakar S, Chowdhury A, Das KP. 2016. Interaction of $\alpha$-crystallin with some small molecules and its effect on its structure and function. Biochim Biophys Acta 1860: 211-221. doi:10.1016/j.bbagen.2015.06.002

Bleackley MR, MacGillivray RTA. 2011. Transition metal homeostasis: From yeast to human disease. BioMetals 24: 785-809. doi:10.1007/s10534-011-9451-4

Bloemendal H. 1977. The vertebrate eye lens. Science 197: 127-138. doi:10.1126/science.877544

Bova MP, Ding LL, Horwitz J, Fung BK. 1997. Subunit exchange of $\alpha$ A-crystallin. J Biol Chem 272: 29511-29517. doi:10.1074/jbc.272.47.29511

Bova MP, Huang Q, Ding L, Horwitz J. 2002. Subunit exchange, conformational stability, and chaperone-like function of the small heat shock protein 16.5 from Methanococcus jannaschii. J Biol Chem 277: 38468-38475. doi:10.1074/jbc.M205594200

Braun N, Zacharias M, Peschek J, Kastenmuller A, Zou J, Hanzlik M, Haslbeck M, Rappsilber J, Buchner J, Weinkauf S. 2011. Multiple molecular architectures of the eye lens chaperone B-crystallin elucidated by a triple hybrid approach. Proc Natl Acad Sci 108: 20491-20496. doi:10 $.1073 /$ pnas.1111014108

Bukach OV, Seit-Nebi AS, Marston SB, Gusev NB. 2004. Some properties of human small heat shock protein Hsp20 (HspB6). Eur J Biochem 271: 291-302. doi:10 $.1046 / \mathrm{j} .1432-1033.2003 .03928 . \mathrm{x}$

Candido EPM. 2002. The small heat shock proteins of the nematode Caenorhabditis elegans: Structure, regulation and biology. Prog Mol Subcell Biol 28: 61-78. doi:10 .1007/978-3-642-56348-5_4

Carra S, Alberti S, Arrigo PA, Benesch JL, Benjamin IJ, Boelens W, Bartelt-Kirbach B, Brundel BJJM, Buchner J, Bukau B, et al. 2017. The growing world of small heat shock proteins: From structure to functions. Cell Stress Chaperones 22: 601-611. doi:10.1007/s12192-017-0787-8

Carter NW, Rector FC, Campion DS, Seldin DW, Seldin DW. 1967. Measurement of intracellular $\mathrm{pH}$ of skeletal muscle with $\mathrm{pH}$-sensitive glass microelectrodes. J Clin Invest 46: 920-933. doi:10.1172/JCI105598

Caspers GJ, Leunissen JAM, de Jong WW. 1995. The expanding small heat-shock protein family, and structure predictions of the conserved " $\alpha$-crystallin domain." J Mol Evol 40: 238-248. doi:10.1007/BF00163229

Cheng C, Nowak RB, Fowler VM. 2017. The lens actin filament cytoskeleton: Diverse structures for complex functions. Exp Eye Res 156: 58-71. doi:10.1016/j.exer.2016.03 .005

Christopher KL, Pedler MG, Shieh B, Ammar DA, Petrash JM, Mueller NH. 2014. $\alpha$-Crystallin-mediated protection of lens cells against heat and oxidative stress-induced cell death. Biochim Biophys Acta 1843: 309-315. doi:10.1016/ j.bbamcr.2013.11.010

Ciaralli L, Giordano R, Costantini S, Sepe A, Cruciani F, Moramarco A, Antonelli B, Balacco-Gabrieli C. 2001. Element concentrations and cataract: An experimental animal model. J Trace Elem Med Biol 14: 205-209. doi: 10.1016/S0946-672X(01)80003-1

Clark AR, Vree Egberts W, Kondrat FDL, Hilton GR, Ray NJ, Cole AR, Carver JA, Benesch JLP, Keep NH, Boelens WC, et al. 2018. Terminal regions confer plasticity to the tet- 
M.K. Janowska et al.

rameric assembly of human HspB2 and HspB3. J Mol Biol 430: 3297-3310. doi:10.1016/j.jmb.2018.06.047

Clouser AF, Klevit RE. 2017. pH-dependent structural modulation is conserved in the human small heat shock protein HSBP1. Cell Stress Chaperones 22: 569-575. doi:10 .1007/s12192-017-0783-z

Cox D, Selig E, Griffin MDW, Carver JA, Ecroyd H. 2016. Small heat-shock proteins prevent $\alpha$-synuclein aggregation via transient interactions and their efficacy is affected by the rate of aggregation. J Biol Chem 291:22618-22629. doi:10.1074/jbc.M116.739250

Cox D, Whiten DR, Brown JWP, Horrocks MH, Gil RS, Dobson CM, Klenerman D, Van Oijen AM, Ecroyd H. 2018. The small heat shock protein Hsp27 binds $\alpha$ synuclein fibrils, preventing elongation and cytotoxicity. J Biol Chem 293: 4486-4497. doi:10.1074/jbc.M117 .813865

Datskevich PN, Nefedova VV, Sudnitsyna MV, Gusev NB. 2012. Mutations of small heat shock proteins and human congenital diseases. Biochem 77: 1500-1514.

Dawczynski J, Blum M, Winnefeld K, Strobel J. 2002. Increased content of zinc and iron in human cataractous lenses. Biol Trace Elem Res 90: 15-24. doi:10.1385/BTER: 90:1-3:15

Delbecq SP, Jehle S, Klevit R. 2012. Binding determinants of the small heat shock protein, $\alpha \mathrm{B}$-crystallin: Recognition of the "IxI" motif. EMBO J 31: 4587-4594. doi:10.1038/ emboj. 2012.318

Delbecq SP, Rosenbaum JC, Klevit RE. 2015. A mechanism of subunit recruitment in human small heat shock protein oligomers. Biochemistry 54: 4276-4284. doi:10.1021/acs .biochem. 5 b00490

Den Engelsman J, Garidel P, Smulders R, Koll H, Smith B, Bassarab S, Seidl A, Hainzl O, Jiskoot W. 2011. Strategies for the assessment of protein aggregates in pharmaceutical biotech product development. Pharm Res 28: 920 933. doi:10.1007/s11095-010-0297-1

De Thonel A, Le Mouël A, Mezger V. 2012. Transcriptional regulation of small HSP - HSF1 and beyond. Int J Biochem Cell Biol 44: 1593-1612. doi:10.1016/j.biocel.2012.06.012

Diokmetzidou A, Soumaka E, Kloukina I, Tsikitis M, Makridakis $\mathrm{M}$, Varela A, Davos CH, Georgopoulos S, Anesti V, Vlahou A, et al. 2016. Desmin and $\alpha \mathrm{B}$-crystallin interplay in the maintenance of mitochondrial homeostasis and cardiomyocyte survival. J Cell Sci 129: 3705-3720. doi:10.1242/jcs.192203

Domínguez-Calva JA, Haase-Pettingell C, Serebryany E, King JA, Quintanar L. 2018. A histidine switch for Zninduced aggregation of $\gamma$-crystallins reveals a metalbridging mechanism that is relevant to cataract disease. Biochemistry 57: 4959-4962. doi:10.1021/acs.biochem .8b00436

Dubińska-Magiera M, Jabłońska J, Saczko J, Kulbacka J, Jagla T, Daczewska M. 2014. Contribution of small heat shock proteins to muscle development and function. FEBS Lett 588: 517-530. doi:10.1016/j.febslet.2014.01 .005

Ecroyd H, Meehan S, Horwitz J, Aquilina JA, Benesch JLP, Robinson CV, Macphee CE, Carver JA. 2007. Mimicking phosphorylation of $\alpha \mathrm{B}$-crystallin affects its chaperone activity. Biochem J 401: 129-141. doi:10.1042/BJ20060981
Fan GC. 2005. Novel cardioprotective role of a small heatshock protein, Hsp20, against ischemia/reperfusion injury. Circulation 111: 1792-1799. doi:10.1161/01.CIR $.0000160851 .41872 . C 6$

Finkel T. 2011. Signal transduction by reactive oxygen species. J Cell Biol 194: 7-15. doi:10.1083/jcb.201102095

Fleckenstein T, Kastenmüller A, Stein ML, Peters C, Daake M, Krause M, Weinfurtner D, Haslbeck M, Weinkauf S, Groll M, et al. 2015. The chaperone activity of the developmental small heat shock protein Sipl is regulated by pH-dependent conformational changes. Mol Cell 58: 1067-1078. doi:10.1016/j.molcel.2015.04.019

Forester BP, Berlow YA, Harper DG, Jensen JE, Lange N, Froimowitz MP, Ravichandran C, Iosifescu DV, Lukas SE, Renshaw PF, et al. 2009. Age-related changes in brain energetics and phospholipid metabolism. NMR Biomed 23: $242-250$.

Fu L, Liang JJN. 2002. Detection of protein-protein interactions among lens crystallins in a mammalian two-hybrid system assay. J Biol Chem 277: 4255-4260. doi:10.1074/ jbc.M110027200

Ganadu ML, Aru M, Mura GM, Coi A, Mlynarz P, Kozlowski H. 2004. Effects of divalent metal ions on the $\alpha \mathrm{B}$ crystallin chaperone-like activity: spectroscopic evidence for a complex between copper(II) and protein. J Inorg Biochem 98: 1103-1109. doi:10.1016/j.jinorgbio.2004.03 .013

Garrido C, Bruey JM, Fromentin A, Hammann A, Arrigo AP, Solary E. 1999. HSP27 inhibits cytochrome c-dependent activation of procaspase-9. FASEB J 13: 2061-2070. doi:10.1096/fasebj.13.14.2061

Hansen L, Yao W, Eiberg H, Kjaer KW, Baggesen K, Hejtmancik JF, Rosenberg T. 2007. Genetic heterogeneity in microcornea-cataract: Five novel mutations in CRYAA, CRYGD, and GJA8. Investig Opthalmology Vis Sci 48: 3937-3944. doi:10.1167/iovs.07-0013

Haslbeck M, Vierling E. 2015. A first line of stress defense: Small heat shock proteins and their function in protein homeostasis. J Mol Biol 427: 1537-1548. doi:10.1016/j .jmb.2015.02.002

Haslbeck M, Walke S, Stromer T, Ehrnsperger M, White HE, Chen S, Saibil HR, Buchner J. 1999. Hsp26: A temperature-regulated chaperone. EMBO J 18: 6744-6751. doi:10 $.1093 / \mathrm{emboj} / 18.23 .6744$

Haslbeck M, Franzmann T, Weinfurtner D, Buchner J. 2005. Some like it hot: The structure and function of small heatshock proteins. Nat Struct Mol Biol 12: 842-846. doi:10 $.1038 / \mathrm{nsmb993}$

Havasi A, Li Z, Wang Z, Martin JL, Botla V, Ruchalski K, Schwartz JH, Borkan SC. 2008. Hsp27 inhibits Bax activation and apoptosis via a phosphatidylinositol 3-kinasedependent mechanism. J Biol Chem 283: 12305-12313. doi:10.1074/jbc.M801291200

Hayes D, Napoli V, Mazurkie A, Stafford WF, Graceffa P. 2009. Phosphorylation dependence of Hsp27 multimeric size and molecular chaperone function. J Biol Chem 284: 18801-18807. doi:10.1074/jbc.M109.011353

Henderson KA, Hughes AL, Gottschling DE. 2014. Motherdaughter asymmetry of $\mathrm{pH}$ underlies aging and rejuvenation in yeast. eLife 3: e03504. doi:10.7554/eLife.03504

Hochberg GKA, Ecroyd H, Liu C, Cox D, Cascio D, Sawaya MR, Collier MP, Stroud J, Carver JA, Baldwin AJ, et al. 
2014. The structured core domain of $\alpha \mathrm{B}$-crystallin can prevent amyloid fibrillation and associated toxicity. Proc Natl Acad Sci 111: E1562-E1570. doi:10.1073/pnas .1322673111

Horwitz J. 1992. $\alpha$-Crystallin can function as a molecular chaperone. Proc Natl Acad Sci 89: 10449-10453.

Horwitz J. 2003. $\alpha$-Crystallin. Exp Eye Res 76: 145-153. doi: 10.1016/S0014-4835(02)00278-6

Houck SA, Landsbury A, Clark JI, Quinlan RA. 2011. Multiple sites in $\alpha B$-crystallin modulate its interactions with desmin filaments assembled in vitro. PLOS ONE 6: e25859. doi:10.1371/journal.pone.0025859

Houlden H, Laura M, Wavrant-De Vrièze F, Blake J, Wood N, Reilly MM. 2008. Mutations in the HSP27 (HSPB1) gene cause dominant, recessive, and sporadic distal HMN/CMT type 2. Neurology 71: 1660-1668. doi:10 $.1212 / 01 . w n l .0000319696 .14225 .67$

Hu Y-B, Dammer EB, Ren RJ, Wang G. 2015. The endosomal-lysosomal system: From acidification and cargo sorting to neurodegeneration. Transl Neurodegener 4: 18. doi:10.1186/s40035-015-0041-1

Huber V, Camisaschi C, Berzi A, Ferro S, Lugini L, Triulzi T, Tuccitto A, Tagliabue E, Castelli C, Rivoltini L. 2017. Cancer acidity: An ultimate frontier of tumor immune escape and a novel target of immunomodulation. Semin Cancer Biol 43: 74-89. doi:10.1016/j.semcancer.2017.03 .001

Irobi J, Van Impe K, Seeman P, Jordanova A, Dierick I, Verpoorten N, Michalik A, De Vriendt E, Jacobs A, Van Gerwen V, et al. 2004. Hot-spot residue in small heat-shock protein 22 causes distal motor neuropathy. Nat Genet 36: 597-601. doi:10.1038/ng1328

Ito H, Kamei K, Iwamoto I, Inaguma Y, Nohara D, Kato K. 2001. Phosphorylation-induced change of the oligomerization state of $\alpha \mathrm{B}$-crystallin. J Biol Chem 276: 5346-5352. doi:10.1074/jbc.M009004200

Jaishankar M, Tseten T, Anbalagan N, Mathew BB, Beeregowda KN. 2014. Toxicity, mechanism and health effects of some heavy metals. Interdiscip Toxicol 7: 60-72. doi:10 .2478/intox-2014-0009

Jakob U, Gaestel M, Engel K, Buchner J. 1993. Small heat shock proteins are molecular chaperones. J Biol Chem 268: 1517-1520.

Jehle S, Vollmar BS, Bardiaux B, Dove KK, Rajagopal P, Gonen T, Oschkinat H, Klevit RE. 2011. N-terminal domain of $\alpha \mathrm{B}$-crystallin provides a conformational switch for multimerization and structural heterogeneity. Proc Natl Acad Sci 108: 6409-6414. doi:10.1073/pnas .1014656108

Jomova K, Valko M. 2011. Advances in metal-induced oxidative stress and human disease. Toxicology 283: 65-87. doi:10.1016/j.tox.2011.03.001

Jovcevski B, Kelly MA, Rote AP, Berg T, Gastall HY, Benesch JLPP, Aquilina JA, Ecroyd H. 2015. Phosphomimics destabilize Hsp27 oligomeric assemblies and enhance chaperone activity. Chem Biol 22: 186-195. doi:10.1016/ j.chembiol.2015.01.001

Juel C. 2008. Regulation of $\mathrm{pH}$ in human skeletal muscle: Adaptations to physical activity. Acta Physiol 193: 17-24. doi:10.1111/j.1748-1716.2008.01840.x
Kamradt MC, Chen F, Sam S, Cryns VL. 2002. The small heat shock protein $\alpha \mathrm{B}$-crystallin negatively regulates apoptosis during myogenic differentiation by inhibiting caspase-3 activation. J Biol Chem 277: 38731-38736. doi:10.1074/jbc.M201770200

Kappé G, Verschuure P, Philipsen RL, Staalduinen AA, Van de Boogaart P, Boelens WC, De Jong WW. 2001. Characterization of two novel human small heat shock proteins: Protein kinase-related HspB8 and testis-specific HspB9. Biochim Biophys Acta 1520: 1-6. doi:10.1016/ S0167-4781(01)00237-8

Kappé G, Franck E, Verschuure P, Boelens WC, Leunissen JAM, de Jong WW. 2003. The human genome encodes 10 $\alpha$-crystallin-related small heat shock proteins: HspB1-10. Cell Stress Chaperones 8: 53-61. doi:10.1379/1466-1268 (2003)8<53:THGECS $>2.0$. CO;2

Karmakar S, Das KP. 2011. Stabilization of oligomeric structure of $\alpha$-crystallin by $\mathrm{Zn}^{+2}$ through intersubunit bridging. Biopolymers 95: 105-116. doi:10.1002/bip.21540

Ketola HG. 1979. Influence of dietary zinc on cataracts in rainbow trout (Salmo gairdneri). J Nutr 109: 965-969. doi:10.1093/jn/109.6.965

Kijima K, Numakura C, Goto T, Takahashi T, Otagiri T, Umetsu K, Hayasaka K. 2005. Small heat shock protein 27 mutation in a Japanese patient with distal hereditary motor neuropathy. J Hum Genet 50: 473-476. doi:10 $.1007 /$ s10038-005-0280-6

Koteiche HA, McHaourab HS. 2003. Mechanism of chaperone function in small heat-shock proteins. Phosphorylation-induced activation of two-mode binding in $\alpha \mathrm{B}$-crystallin. J Biol Chem 278: 10361-10367. doi:10 $.1074 /$ jbc.M211851200

Krieg BJ, Taghavi SM, Amidon GL, Amidon GE. 2014. In vivo predictive dissolution: Transport analysis of the $\mathrm{CO}_{2}$, bicarbonate in vivo buffer system. J Pharm Sci 103: 34733490. doi:10.1002/jps.24108

Kulig M, Ecroyd H. 2012. The small heat-shock protein $\alpha \mathrm{B}$ crystallin uses different mechanisms of chaperone action to prevent the amorphous versus fibrillar aggregation of $\alpha$-lactalbumin. Biochem J 448: 343-352. doi:10.1042/ BJ20121187

Laskowska E, Wawrzynów A, Taylor A. 1996. IbpA and $\mathrm{IbpB}$, the new heat-shock proteins, bind to endogenous Escherichia coli proteins aggregated intracellularly by heat shock. Biochimie 78: 117-122. doi:10.1016/0300-9084 (96) $82643-5$

Leak RK. 2014. Heat shock proteins in neurodegenerative disorders and aging. J Cell Commun Signal 8: 293-310. doi:10.1007/s12079-014-0243-9

Liao WC, Juo LY, Shih YL, Chen YH, Yan YT. 2017. HSPB7 prevents cardiac conduction system defect through maintaining intercalated disc integrity. PLoS Genet 13: e1006984. doi:10.1371/journal.pgen.1006984

Lindberg DJ, Wranne MS, Gilbert Gatty M, Westerlund F, Esbjörner EK. 2015. Steady-state and time-resolved thioflavin-T fluorescence can report on morphological differences in amyloid fibrils formed by $A \beta(1-40)$ and A $\beta(1-42)$. Biochem Biophys Res Commun 458: 418-423. doi:10.1016/j.bbrc.2015.01.132

Litt M, Kramer P, LaMorticella DM, Murphey W, Lovrien EW, Weleber RG. 1998. Autosomal dominant congenital cataract associated with a missense mutation in the 
M.K. Janowska et al.

human $\alpha$-crystallin gene CRYAA. Hum Mol Genet 7: 471-474. doi:10.1093/hmg/7.3.471

Liu JP, Schlosser R, Ma WY, Dong Z, Feng H, Liu L, Huang XQ, Liu Y, Li DWC. 2004. Human $\alpha$ A- and $\alpha B$-crystallins prevent UVA-induced apoptosis through regulation of $\mathrm{PKC} \alpha, \mathrm{RAF} / \mathrm{MEK} / \mathrm{ERK}$ and AKT signaling pathways. Exp Eye Res 79: 393-403. doi:10.1016/j.exer.2004.06.015

Liu J, Zhang D, Mi X, Xia Q, Yu Y, Zuo Z, Guo W, Zhao X, Cao J, Yang Q, et al. 2010. p27 suppresses arseniteinduced Hsp27/Hsp70 expression through inhibiting JNK2/c-Jun- and HSF-1-dependent pathways. J Biol Chem 285: 26058-26065. doi:10.1074/jbc.M110.100271

Liu Z, Wang C, Li Y, Zhao C, Li T, Li D, Zhang S, Liu C. 2018. Mechanistic insights into the switch of $\alpha \mathrm{B}$-crystallin chaperone activity and self-multimerization. J Biol Chem 293: 14880-14890. doi:10.1074/jbc.RA118.004034

Lomiwes D, Farouk MM, Wiklund E, Young OA. 2014. Small heat shock proteins and their role in meat tenderness: A review. Meat Sci 96: 26-40. doi:10.1016/j.meatsci .2013 .06 .008

Longo DL, Cutrin JC, Michelotti F, Irrera P, Aime S. 2017. Noninvasive evaluation of renal $\mathrm{pH}$ homeostasis after ischemia reperfusion injury by CEST-MRI. NMR Biomed 30: e3720. doi:10.1002/nbm.3720

Lynnerup N, Kjeldsen H, Heegaard S, Jacobsen C, Heinemeier J. 2008. Radiocarbon dating of the human eye lens crystallines reveal proteins without carbon turnover throughout life. PLOS ONE 3: e1529. doi:10.1371/ journal.pone.0001529

Mainz A, Bardiaux B, Kuppler F, Multhaup G, Felli IC, Pierattelli R, Reif B. 2012. Structural and mechanistic implications of metal binding in the small heat-shock protein $\alpha$ B-crystallin. J Biol Chem 287: 1128-1138. doi:10.1074/jbc.M111.309047

Mainz A, Peschek J, Stavropoulou M, Back KC, Bardiaux B, Asami S, Prade E, Peters C, Weinkauf S, Buchner J, et al. 2015. The chaperone $\alpha \mathrm{B}$-crystallin uses different interfaces to capture an amorphous and an amyloid client. Nat Struct Mol Biol 22: 898-905. doi:10.1038/nsmb.3108

Majdi A, Mahmoudi J, Sadigh-Eteghad S, Golzari SEJ, Sabermarouf B, Reyhani-Rad S. 2016. Permissive role of cytosolic $\mathrm{pH}$ acidification in neurodegeneration: A closer look at its causes and consequences. J Neurosci Res 94: 879887. doi:10.1002/jnr.23757

Maloyan A. 2005. Mitochondrial dysfunction and apoptosis underlie the pathogenic process in $\alpha$-B-crystallin desminrelated cardiomyopathy. Circulation 112: 3451-3461. doi:10.1161/circulationaha.105.572552

Martin JL, Mestril R, Hilal-Dandan R, Brunton LL, Dillmann WH. 1997. Small heat shock proteins and protection against ischemic injury in cardiac myocytes. Circulation 96: 4343-4348. doi:10.1161/01.CIR.96.12.4343

Martín-Folgar R, Martínez-Guitarte JL. 2017. Cadmium alters the expression of small heat shock protein genes in the aquatic midge Chironomus riparius. Chemosphere 169: 485-492. doi:10.1016/j.chemosphere.2016.11.067

Marzouk SAM, Buck RP, Dunlap LA, Johnson TA, Cascio WE. 2002. Measurement of extracellular $\mathrm{pH}, \mathrm{K}^{+}$, and lactate in ischemic heart. Anal Biochem 308: 52-60. doi:10 .1016/S0003-2697(02)00220-8

McDonald ET, Bortolus M, Koteiche HA, McHaourab HS. 2012. Sequence, structure, and dynamic determinants of
Hsp27 (HspB1) equilibrium dissociation are encoded by the N-terminal domain. Biochemistry 51: 1257-1268. doi:10.1021/bi2017624

McVicar N, Li AX, Gonçalves DF, Bellyou M, Meakin SO, Prado MA, Bartha R. 2014. Quantitative tissue pH measurement during cerebral ischemia using amine and amide concentration-independent detection (AACID) with MRI. J Cereb Blood Flow Metab 34: 690-698. doi:10.1038/ jcbfm.2014.12

Meehan S, Knowles TPJ, Baldwin AJ, Smith JF, Squires AM, Clements P, Treweek TM, Ecroyd H, Tartaglia GG, Vendruscolo M, et al. 2007. Characterisation of amyloid fibril formation by small heat-shock chaperone proteins human $\alpha \mathrm{A}-, \alpha \mathrm{B}$ - and R120G $\alpha \mathrm{B}$-crystallins. J Mol Biol 372: 470-484. doi:10.1016/j.jmb.2007.06.060

Michael R, Bron AJ. 2011. The ageing lens and cataract: A model of normal and pathological ageing. Philos Trans $R$ Soc Lond B Biol Sci 366: 1278-1292. doi:10.1098/rstb .2010 .0300

Michaud S, Morrow G, Marchand J, Tanguay RM. 2002. Drosophila small heat shock proteins: Cell and organelle-specific chaperones? Prog Mol Subcell Biol 28: 79101. doi:10.1007/978-3-642-56348-5_5

Morrison LE, Hoover HE, Thuerauf DJ, Glembotski CC. 2003. Mimicking phosphorylation of $\alpha \mathrm{B}$-crystallin on serine-59 is necessary and sufficient to provide maximal protection of cardiac myocytes from apoptosis. Circ Res 92: 203-211. doi:10.1161/01.RES.0000052989.83995.A5

Mounier N, Arrigo AP. 2002. Actin cytoskeleton and small heat shock proteins: How do they interact? Cell Stress Chaperones 7: 167-176. doi:10.1379/1466-1268(2002) $007<0167$ :ACASHS $>2.0$.CO;2

Moura A, Savageau MA, Alves R. 2013. Relative amino acid composition signatures of organisms and environments. PLoS ONE 8: e77319. doi:10.1371/journal.pone.0077319

Muchowski PJ, Valdez MM, Clark JI. 1999. $\alpha$ B-crystallin selectively targets intermediate filament proteins during thermal stress. Invest Ophthalmol Vis Sci 40: 951-958.

Mymrikov EV, Daake M, Richter B, Haslbeck M, Buchner J. 2017. The chaperone activity and substrate spectrum of human small heat shock proteins. J Biol Chem 292: 672684. doi:10.1074/jbc.M116.760413

Nemes Z, Devreese B, Steinert PM, Van Beeumen J, Fésüs L. 2004. Cross-linking of ubiquitin, HSP27, parkin, and $\alpha$ synuclein by $\gamma$-glutamyl- $\varepsilon$-lysine bonds in Alzheimer's neurofibrillary tangles. FASEB J 18: 1135-1137. doi:10 .1096/fj.04-1493fje

Nicholl ID, Quinlan RA. 1994. Chaperone activity of $\alpha$-crystallins modulates intermediate filament assembly. $E M B O$ $J$ 13: 945-953. doi:10.1002/j.1460-2075.1994.tb06339.x

Pereira P, Shang F, Hobbs M, Girão H, Taylor A. 2003. Lens fibers have a fully functional ubiquitin-proteasome pathway. Exp Eye Res 76: 623-631. doi:10.1016/S0014-4835 (03)00020-4

Peschek J, Braun N, Rohrberg J, Back KC, Kriehuber T, Kastenmüller A, Weinkauf S, Buchner J. 2013. Regulated structural transitions unleash the chaperone activity of $\alpha B$-crystallin. Proc Natl Acad Sci 110: E3780-E3789. doi:10.1073/pnas.1308898110

Posner M, Kiss AJ, Skiba J, Drossman A, Dolinska MB, Hejtmancik JF, Sergeev YV. 2012. Functional validation of hydrophobic adaptation to physiological temperature 
in the small heat shock protein $\alpha \mathrm{A}$-crystallin. PLoS ONE 7: e34438. doi:10.1371/journal.pone.0034438

Prabhu S, Srinivas V, Ramakrishna T, Raman B, Rao CM. 2011. Inhibition of $\mathrm{Cu}^{2+}$-mediated generation of reactive oxygen species by the small heat shock protein $\alpha \mathrm{B}$-crystallin: The relative contributions of the $\mathrm{N}$ - and C-terminal domains. Free Radic Biol Med 51: 755-762. doi:10.1016/j.freeradbiomed.2011.05.021

Préville X, Salvemini F, Giraud S, Chaufour S, Paul C, Stepien G, Ursini MV, Arrigo AP. 1999. Mammalian small stress proteins protect against oxidative stress through their ability to increase glucose-6-phosphate dehydrogenase activity and by maintaining optimal cellular detoxifying machinery. Exp Cell Res 247: 61-78. doi:10.1006/excr .1998 .4347

Quintanar L, Domínguez-Calva JA, Serebryany E, RivillasAcevedo L, Haase-Pettingell C, Amero C, King JA. 2016. Copper and zinc ions specifically promote nonamyloid aggregation of the highly stable human $\gamma$-D crystallin ACS Chem Biol 11: 263-272. doi:10.1021/acschembio $.5 \mathrm{~b} 00919$

Rajagopal P, Liu Y, Shi L, Clouser AF, Klevit RE. 2015a. Structure of the $\alpha$-crystallin domain from the redox-sensitive chaperone, HSPB1. J Biomol NMR 63: 223-228. doi:10.1007/s10858-015-9973-0

Rajagopal P, Tse E, Borst AJ, Delbecq SP, Shi L, Southworth DR, Klevit RE. 2015b. A conserved histidine modulates HSPB5 structure to trigger chaperone activity in response to stress-related acidosis. eLife 4: e07304. doi:10.7554/ eLife.07304

Rauch JN, Tse E, Freilich R, Mok SA, Makley LN, Southworth DR, Gestwicki JE. 2017. BAG3 is a modular, scaffolding protein that physically links heat shock protein 70 (Hsp70) to the small heat shock proteins. J Mol Biol 429: 128-141. doi:10.1016/j.jmb.2016.11.013

Reichmann D, Voth W, Jakob U. 2018. Maintaining a healthy proteome during oxidative stress. Mol Cell 69: 203-213. doi:10.1016/j.molcel.2017.12.021

Rogalla T, Ehrnsperger M, Preville X, Kotlyarov A, Lutsch G, Ducasse C, Paul C, Wieske M, Arrigo APP, Buchner J, et al. 1999. Regulation of Hsp27 oligomerization, chaperone function, and protective activity against oxidative stress/ tumor necrosis factor $\alpha$ by phosphorylation. J Biol Chem 274: 18947-18956. doi:10.1074/jbc.274.27.18947

Scharf KD, Siddique M, Vierling E. 2001. The expanding family of Arabidopsis thaliana small heat stress proteins and a new family of proteins containing $\alpha$-crystallin domains (Acd proteins). Cell Stress Chaperones 6: 225-237. doi:10 .1379/1466-1268(2001)006<0225:TEFOAT>2.0.CO;2

Sharp FR, Zhan X, Liu D-Z. 2013. Heat shock proteins in the brain: Role of Hsp70, Hsp 27, and HO-1 (Hsp32) and their therapeutic potential. Transl Stroke Res 4: 685692. doi:10.1007/s12975-013-0271-4

Shashidharamurthy R, Koteiche HA, Dong J, McHaourab HS. 2005. Mechanism of chaperone function in small heat shock proteins: Dissociation of the HSP27 oligomer is required for recognition and binding of destabilized T4 lysozyme. J Biol Chem 280: 5281-5289. doi:10.1074/jbc .M407236200

Shimura H, Miura-Shimura Y, Kosik KS. 2004. Binding of tau to heat shock protein 27 leads to decreased concentration of hyperphosphorylated tau and enhanced cell survival. J Biol Chem 279: 17957-17962. doi:10.1074/jbc .M400351200

Shirmanova MV, Druzhkova IN, Lukina MM, Matlashov ME, Belousov VV, Snopova LB, Prodanetz NN, Dudenkova VV, Lukyanov SA, Zagaynova EV. 2015. Intracellular $\mathrm{pH}$ imaging in cancer cells in vitro and tumors in vivo using the new genetically encoded sensor SypHer2. Biochim Biophys Acta 1850: 1905-1911. doi:10.1016/j .bbagen.2015.05.001

Sies H, Berndt C, Jones DP. 2017. Oxidative stress. Annu Rev Biochem 86: 715-748. doi:10.1146/annurev-biochem061516-045037

Sluchanko NN, Beelen S, Kulikova AA, Weeks SD, Antson AA, Gusev NB, Strelkov SV. 2017. Structural basis for the interaction of a human small heat shock protein with the 14-3-3 universal signaling regulator. Structure 25: 305316. doi:10.1016/j.str.2016.12.005

Smulders RHPH, Carver JA, Lindner RA, Van Boekel MAM, Bloemendal H, De Jong WW. 1996. Immobilization of the C-terminal extension of bovine $\alpha \mathrm{A}$-crystallin reduces chaperone-like activity. J Biol Chem 271: 29060-29066. doi:10.1074/jbc.271.46.29060

Srivastava OP, Srivastava K, Chaves JM, Gill AK. 2017. Posttranslationally modified human lens crystallin fragments show aggregation in vitro. Biochem Biophys Rep 10: 94131.

Stetler RA, Gao Y, Zhang L, Weng Z, Zhang F, Hu X, Wang S, Vosler P, Cao G, Sun D, et al. 2012. Phosphorylation of HSP27 by protein kinase D is essential for mediating neuroprotection against ischemic neuronal injury. J Neurosci 32: 2667-2682. doi:10.1523/jneurosci.516911.2012

Street D, Bangsbo J, Juel C. 2001. Interstitial pH in human skeletal muscle during and after dynamic graded exercise. J Physiol 537: 993-998. doi:10.1113/jphysiol.2001 .012954

Sugiyama Y, Suzuki A, Kishikawa M, Akutsu R, Hirose T, Waye MM, Tsui SK, Yoshida S, Ohno S. 2000. Muscle develops a specific form of small heat shock protein complex composed of MKBP/HSPB2 and HSPB3 during myogenic differentiation. J Biol Chem 275: 1095-1104. doi:10.1074/jbc.275.2.1095

Susek RE, Lindquist SL. 1989. hsp26 of Saccharomyces cerevisiae is related to the superfamily of small heat shock proteins but is without a demonstrable function. $\mathrm{Mol}$ Cell Biol 9: 5265-5271. doi:10.1128/MCB.9.11.5265

Takemoto L, Sorensen CM. 2008. Protein-protein interactions and lens transparency. Exp Eye Res 87: 496-501. doi:10.1016/j.exer.2008.08.018

Treweek TM, Meehan S, Ecroyd H, Carver JA. 2015. Small heat-shock proteins: Important players in regulating cellular proteostasis. Cell Mol Life Sci 72: 429-451. doi:10 .1007/s00018-014-1754-5

Unger A, Beckendorf L, Böhme P, Kley R, von Frieling-Salewsky M, Lochmüller H, Schröder R, Fürst DO, Vorgerd M Linke WA. 2017. Translocation of molecular chaperones to the titin springs is common in skeletal myopathy patients and affects sarcomere function. Acta Neuropathol Commun 5: 72. doi:10.1186/s40478-017-0474-0

Vicart P, Caron A, Guicheney P, Li Z, Prévost MC, Faure A, Chateau D, Chapon F, Tomé F, Dupret JM, et al. 1998. A missense mutation in the $\alpha \mathrm{B}$-crystallin chaperone gene 
M.K. Janowska et al.

causes a desmin-related myopathy. Nat Genet 20: 92-95. doi:10.1038/1765

Wales TS, Yang D, John G, Ali F, Blais A, McDermott JC. 2016. Regulation of Hspb7 by MEF2 and AP-1: Implications for Hspb7 in muscle atrophy. J Cell Sci 129: jcs.190009. doi:10.1242/jcs.190009

Walsh MT, Sen AC, Chakrabarti B. 1991. Micellar subunit assembly in a three-layer model of oligomeric $\alpha$ crystallin. J Biol Chem 266: 20079-20084.

Wang K, Spector A. 1995. $\alpha$-crystallin can act as a chaperone under conditions of oxidative stress. Invest Ophthalmol Vis Sci 36: 311-321.

Weeks SD, Baranova EV, Heirbaut M, Beelen S, Shkumatov AV, Gusev NB, Strelkov SV. 2014. Molecular structure and dynamics of the dimeric human small heat shock protein HSPB6. J Struct Biol 185: 342-354. doi:10.1016/ j.jsb.2013.12.009

Wotton D, Freeman K, Shore D. 1996. Multimerization of Hsp42p, a novel heat shock protein of Saccharomyces cerevisiae, is dependent on a conserved carboxyl-terminal sequence. J Biol Chem 271: 2717-2723. doi:10.1074/jbc .271 .5 .2717

Wray S. 1988. Smooth muscle intracellular $\mathrm{pH}$ : Measurement, regulation, and function. Am J Physiol 254: C213-C225. doi:10.1152/ajpcell.1988.254.2.C213

Yanshole LV, Cherepanov IV, Snytnikova OA, Yanshole VV, Sagdeev RZ, Tsentalovich YP. 2013. Cataract-specific posttranslational modifications and changes in the composition of urea-soluble protein fraction from the rat lens. Mol Vis 19: 2196-2208.

Zhong YH, Cheng HZ, Peng H, Tang SC, Wang P. 2016. Heat shock factor 2 is associated with the occurrence of lung cancer by enhancing the expression of heat shock proteins. Oncol Lett 12: 5106-5112. doi:10.3892/ol.2016 .5368

Zoubeidi A, Gleave M. 2012. Small heat shock proteins in cancer therapy and prognosis. Int J Biochem Cell Biol 44: 1646-1656. doi:10.1016/j.biocel.2012.04.010 


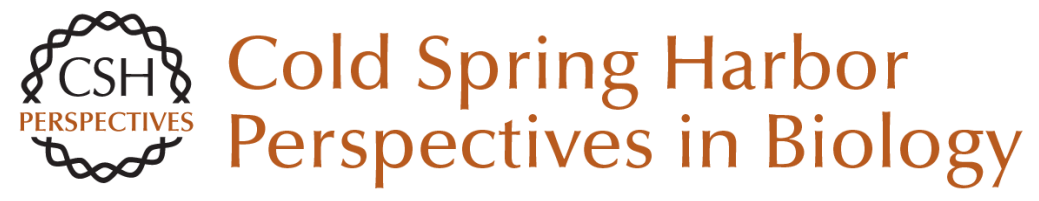

\section{Mechanisms of Small Heat Shock Proteins}

Maria K. Janowska, Hannah E.R. Baughman, Christopher N. Woods and Rachel E. Klevit

Cold Spring Harb Perspect Biol 2019; doi: 10.1101/cshperspect.a034025 originally published online March 4, 2019

\section{Subject Collection Protein Homeostasis}

Proteome-Scale Mapping of Perturbed

Proteostasis in Living Cells

Isabel Lam, Erinc Hallacli and Vikram Khurana

Pharmacologic Approaches for Adapting Proteostasis in the Secretory Pathway to

Ameliorate Protein Conformational Diseases Jeffery W. Kelly

Cell-Nonautonomous Regulation of Proteostasis in Aging and Disease

Richard I. Morimoto

The Autophagy Lysosomal Pathway and

Neurodegeneration

Steven Finkbeiner

Functional Modules of the Proteostasis Network Gopal G. Jayaraj, Mark S. Hipp and F. Ulrich Hartl

Protein Solubility Predictions Using the CamSol Method in the Study of Protein Homeostasis Pietro Sormanni and Michele Vendruscolo

Recognition and Degradation of Mislocalized Proteins in Health and Disease

Ramanujan S. Hegde and Eszter Zavodszky

The Nuclear and DNA-Associated Molecular Chaperone Network

Zlata Gvozdenov, Janhavi Kolhe and Brian C. Freeman
The Amyloid Phenomenon and Its Significance in Biology and Medicine

Christopher M. Dobson, Tuomas P.J. Knowles and Michele Vendruscolo

A Chemical Biology Approach to the Chaperome

in Cancer--HSP90 and Beyond

Tony Taldone, Tai Wang, Anna Rodina, et al.

Proteostasis in Viral Infection: Unfolding the Complex Virus-Chaperone Interplay Ranen Aviner and Judith Frydman

The Proteasome and Its Network: Engineering for Adaptability Daniel Finley and Miguel A. Prado

Functional Amyloids Daniel Otzen and Roland Riek

Chaperone Interactions at the Ribosome Elke Deuerling, Martin Gamerdinger and Stefan G. Kreft

Mechanisms of Small Heat Shock Proteins Maria K. Janowska, Hannah E.R. Baughman, Christopher N. Woods, et al.

Structure, Function, and Regulation of the Hsp90 Machinery

Maximilian M. Biebl and Johannes Buchner

For additional articles in this collection, see http://cshperspectives.cshlp.org/cgi/collection/

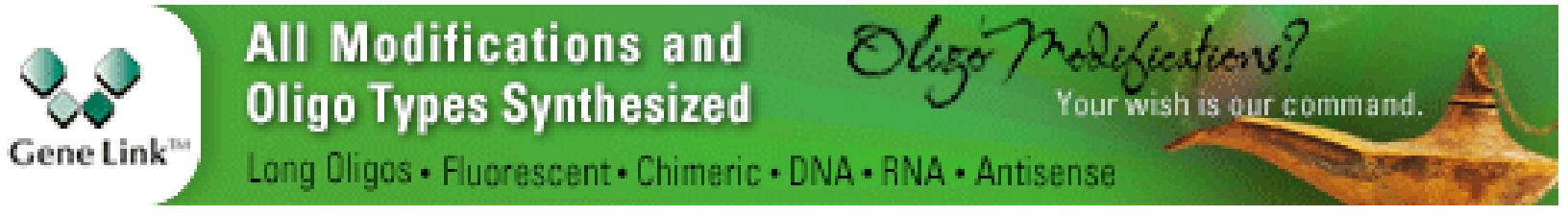


For additional articles in this collection, see http://cshperspectives.cshlp.org/cgi/collection/

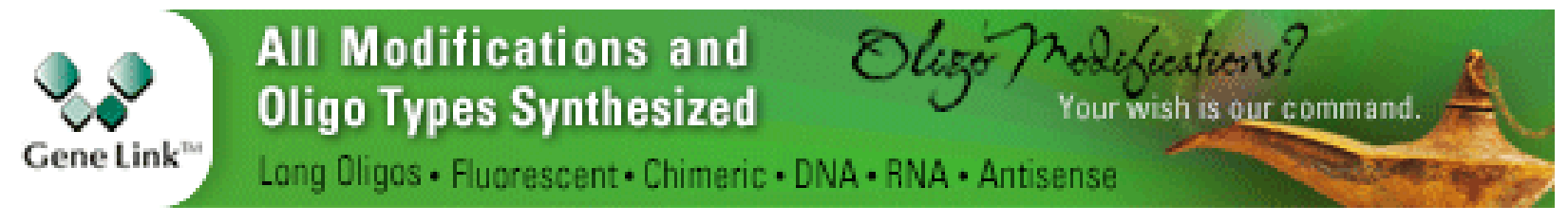

Copyright @ 2019 Cold Spring Harbor Laboratory Press; all rights reserved 